\title{
Modelo de avaliação de satisfação dos agricultores familiares em relação ao programa de aquisição de alimentos do Governo Federal
}

\section{Satisfaction evaluation model of family farmers in relation to the food acquisition program of the Federal Government}

\author{
DANIEL TEOTONIO DO NASCIMENTO* \\ JERRY ADRIANI JOHANN** \\ DIRCEU BASSO***
}

\section{RESUMO}

As receitas arrecadadas pelo Estado são quase sempre insuficientes para atender a todas as demandas da cidadania, portanto, é primordial uma aplicação eficiente dos recursos estatais nas políticas públicas implementadas. Quando se avaliam as políticas públicas, toda a sociedade é beneficiada com os resultados, pois em base aos diagnósticos, algumas ações podem ser melhoradas e outras redirecionadas. Este artigo teve como propósito desenvolver um Modelo de Avaliação de Satisfação (MAS) dos agricultores familiares em relação ao Programa de Aquisição de Alimentos (PAA), modalidade Compra com Doação Simultânea (CDS). O MAS possui duas finalidades: a) detectar o grau de satisfação dos agricultores familiares em relação à política pública PAA; e b) avaliar o grau de satisfação dos agricultores familiares em relação à gestão das cooperativas ou associações. Em base à literatura e legislações correlatas ao tema, alcançou-se um modelo

* Doutorando em Administração pela Universidade Federal do Mato Grosso do Sul (UFMS). Mestre em Administração - UNIOESTE, Administrador na Universidade Federal da Integração Latino-Americana. danielteotonio@hotmail.com .

** Doutor em Engenharia Agrícola pela UNICAMP. Docente Adjunto da UNIOESTE dos cursos de pós-graduação em Engenharia Agrícola, mestrado Profissional em Administração e mestrado em Ciências Contábeis. jerry.johann@hotmail.com .

*** Doutor em Desenvolvimento Rural pela Universidade Federal do Rio Grande do Sul. Docente da UNILA do curso de graduação em Desenvolvimento Rural e Segurança Alimentar.dirceu.basso@unila.edu.br . 
inovador e abrangente, com grande potencial de aplicabilidade. O modelo pretende contribuir para uma maior efetividade na coleta padronizada de percepções sobre o PAA, posto que o MAS poderá ser aplicado em qualquer região do Brasil, possibilitando ajustes operacionais e socioeconômicos pelos órgãos públicos e cooperativas, melhorando dessa forma a eficiência da política pública e dos processos organizacionais das cooperativas.

Palavras-chave: Programa de Aquisição de Alimentos (PAA). Modelo de Avaliação de Satisfação (MAS). Políticas Públicas. Agricultor Familiar. Compra com Doação Simultânea (CDS).

\section{Abstract}

The revenues collected by the State are almost always insufficient to meet all the demands of citizenship, therefore, it is essential an efficient application of state resources in the public policies implemented. When evaluating public policies the whole society benefits with the results, because on the basis of the diagnoses, some actions can be improved and others can be redirected. This article aimed to develop a Satisfaction Evaluation Model of the family farmers in relation to the Food Acquisition Program, the mode Purchase with Simultaneous Donation. The Satisfaction Evaluation Model has two purposes: a) to detect the grade of satisfaction of family farmers about the public policy, Food Acquisition Program; and b) to assess the grade of satisfaction of family farmers about the management of the cooperatives or associations. On the basis of literature and related legislation to the subject, reached up an innovative and comprehensive model, with great potential for applicability. The model aims to contribute to a greater effectiveness in the standardized collection of perceptions about Food Acquisition Progra, since the model can be applied in any region of Brazil, enabling operational and socio-economic adjustments by the public agencies and cooperatives, thereby improving the efficiency of public policy and the organizational processes of cooperatives.

Key-words: Food Acquisition Program. Satisfaction Evaluation Model. Public Policies. Family Farmers. Purchase with Simultaneous Donation. 


\section{INTRODUÇÃo}

A participação social nos processos de discussão, elaboração, gestão e controle das políticas públicas foi uma das principais reivindicações defendida pelos agentes sociais no processo de redemocratização brasileiro - ocorrido na década de 1980. Como efeito dessa mobilização, a Constituição Federal de 1988 introduziu novos instrumentos de gestão social das políticas públicas, o que motivou o início da participação da sociedade civil nas ações governamentais, como foi o caso dos atores relacionados com a agricultura familiar (SILVA; MARQUES, 2009).

Nota-se que a dívida histórica com a agricultura familiar começou a ser saldada somente a partir dos anos 90, pois apesar de a agricultura familiar desempenhar um importante papel na segurança alimentar e na geração de empregos no campo, o Estado sempre lhe dispensou um tratamento marginal ou secundário (MAIA, 2009).

Em virtude do reconhecimento da multifuncionalidade da agricultura familiar durante as últimas duas décadas, o setor rural passou a despertar mais a atenção dos agentes públicos e da sociedade. Segundo o Censo Agropecuário de 2006, a agricultura familiar contava com cerca de 4,4 milhões de estabelecimentos, respondia por $38 \%$ do valor total da produção agropecuária com um valor de R\$ 54,4 bilhões, era responsável pela segurança alimentar e empregava $74,4 \%$ da mão de obra no campo, ou seja, 12,3 milhões de trabalhadores, além do gerenciamento de uma área de 80,25 milhões de hectares (INSTITUTO BRASILEIRO DE GEOGRAFIA E ESTATÍSTICA, 2006).

Além desses atributos, outra multifuncionalidade importante da agricultura familiar refere-se à sua relação mais respeitosa com o meio ambiente, passando a ser uma opção mais sustentável, se comparada com o modelo convencional agrícola (CARNEIRO; MALUF, 2003).

Nesse contexto de tentativa de valorização da agricultura familiar, o Governo criou em 28 junho de 1996, por meio do Decreto n.o 1.946 (1996), o Programa Nacional de Fortalecimento da Agricultura Familiar (PRONAF), com a finalidade de promover o desenvolvimento sustentável do segmento rural, constituído pelos agricultores familiares, de modo a lhes propiciar o aumento da capacidade produtiva, a geração de empregos e a melhoria de renda. 
Foi a partir da institucionalização do Pronaf que o conceito do termo "agricultura familiar" tornou-se menos ideológico e mais operacional, estabelecendo critérios e características para acessar o programa governamental.

Outras políticas públicas complementares também foram desenvolvidas nos últimos anos, talvez visando corrigir imperfeições do Pronaf e, ao mesmo tempo, buscando sintonia com o Programa Fome Zero - como é o caso do Programa de Aquisição de Alimentos (PAA), instituído em junho de 2003. O PAA, como é mais conhecido, é uma política pública em que são adquiridos alimentos dos agricultores familiares que se enquadram no Pronaf, sendo esses alimentos destinados à formação de estoques de segurança ou canalizados para populações em situação de risco alimentar (COMPANHIA NACIONAL DE ABASTECIMENTO, 2009; GRISA; SCHNEIDER, 2014; TANACA; SOUZA; GANGA, 2014).

Na atualidade, o PAA é operacionalizado através de seis importantes modalidades distintas, porém o foco deste artigo esteve centrado na modalidade de Compra com Doação Simultânea (CDS). Participam do PAA a União, Estados, Distrito Federal e Municípios. O grau de envolvimento de cada ente é estabelecido de acordo com a modalidade. No âmbito federal, a maioria das modalidades é gerenciada pelo Ministério de Desenvolvimento Social (MDS), com a cooperação efetiva da Companhia Nacional de Abastecimento (CONAB) na operacionalização do programa, sendo o elo entre os Estados, municípios e os agricultores familiares.

Desde 2003, o PAA vem aumentando seu campo de atuação, atendendo cada vez mais aos beneficiários, sejam recebedores - pessoas com risco de insegurança alimentar -, ou fornecedores - agricultores familiares. A modalidade compra com Doação Simultânea (CDS) é a que possui maior movimentação nas operações, tanto em volume de recursos, como em número de agricultores familiares atendidos. Assim, descreve a CONAB (2016) que os objetivos da modalidade de Compra com Doação Simultânea devem "promover a articulação entre a produção da agricultura familiar e a destinação dessa produção, visando o atendimento direto às demandas de alimentação ou de suplementação alimentar e nutricional dos programas sociais e o desenvolvimento da economia local". 
Considerando a importância dessa política pública para o meio rural, sendo de abrangência nacional, torna-se imprescindível verificar o grau de satisfação de um de seus principais atores, que são os agricultores familiares, pois são eles que desencadeiam todo o processo da política pública PAA, e sem a efetiva participação desses pequenos agricultores, as metas do programa não seriam alcançadas.

Alguns estudos já abordaram os impactos do PAA, diretos ou indiretos para os agricultores familiares. Tais pesquisas revelam que os impactos são diferenciados, a depender da modalidade do PAA, da região, das entidades participantes e das unidades executoras. Nascimento et al. (2015) consolidaram esses resultados em cincos categorias: resultados positivos; resultados positivos e negativos de maneira concomitante; resultados pouco perceptíveis, porém negativos; resultados pouco perceptíveis, porém positivos. Ressalta-se que em nenhum estudo verificou-se somente impactos negativos do PAA. Assim, foram observadas debilidades em alguns indicadores do PAA. Essas debilidades estariam relacionadas à falta de capacitação para os agricultores familiares e para a gestão das cooperativas ou associações; com a falta de parcerias locais; com o baixo valor por produtor e com o baixo limite de entrega por agricultor.

Observou-se que não houve, nos estudos realizados, uma preocupação em desenvolver um modelo de avaliação representativo, com variedade de indicadores, e que pudesse ser aplicado a produtores de outras regiões.

Considerando que a cidadania moderna não tolera ineficácia por parte do Estado, faz-se necessário um acompanhamento constante das políticas públicas em execução. Dessa forma, o objetivo deste artigo foi desenvolver um modelo para a avaliação da política pública PAA, modalidade Compra com Doação Simultânea (CDS), capaz de detectar o grau de satisfação dos agricultores familiares, em relação aos aspectos operacionais e socioeconômicos do programa público.

O problema de pesquisa deu-se pela verificação da falta de um modelo representativo e abrangente, para a avaliação do Programa de Aquisição de Alimentos, que fosse capaz de identificar o grau de satisfação dos agricultores familiares - um de seus principais atores. Isso tem impossibilitado, de certa maneira, os ajustes necessários para a melhoria do programa. Conforme já destacado, os modelos 
avaliativos existentes tiveram propósitos mais específicos e focados em realidades locais.

Diante do exposto, para se alcançar o objetivo principal deste estudo se propôs a seguinte questão de pesquisa: É possível desenvolver um modelo de avaliação do grau de satisfação dos agricultores familiares, em relação aos aspectos operacionais e socioeconômicos do Programa de Aquisição de Alimentos (PAA), modalidade Compra com Doação Simultânea (CDS)?

Esta pesquisa contribui com o campo de avaliações de políticas públicas, bem como, para uma maior visibilidade dos agricultores familiares. As políticas públicas são elaboradas e executadas com o intuito de resolver problemas de determinados coletivos. Entre os problemas, destacam-se aqueles relacionados à maneira de os agricultores familiares e suas organizações se inserirem nos mercados. Diante disso, faz-se necessário o desenvolvimento de metodologias para avaliar o desempenho do programa público.

Como resultado desta pesquisa, alcançou-se um Modelo de Avaliação de Satisfação (MAS) dos agricultores familiares, inovador e abrangente, capaz de detectar o grau de suas satisfações ou insatisfações, em relação aos aspectos operacionais e socioeconômicos do PAA, e em relação às suas percepções em relação à gestão das cooperativas e associações.

\section{FUNDAMENTAÇÃo TEÓRICA}

Nesta seção, foram abordadas as temáticas da agricultura familiar; cooperativismo; políticas públicas; o Programa de Aquisição de Alimentos (PAA); bem como, os estudos anteriores sobre o tema; e os indicadores fundamentais para a avaliação do Programa de Aquisição de Alimentos.

\subsection{Agricultura Familiar}

A pequena propriedade rural tem passado por significativas mudanças desde a década de 1970. Esse cenário de instabilidade forçou os agricultores familiares a se unirem e a defenderem seus espaços como atores protagonistas do desenvolvimento rural brasileiro.

Apesar de a agricultura familiar ocupar um importante papel na segurança alimentar e no abastecimento interno, esse setor sempre 
conviveu com uma dicotomia, pois o Estado sempre lhe dispensou um tratamento secundário. Somente nos últimos anos houve um planejamento de políticas públicas voltadas a esse segmento rural (SILVA; MARQUES, 2009).

Embora o avanço do debate social e acadêmico, nota-se que não há um entendimento único, uma exclusividade e delimitação estrita do conceito de agricultura familiar, apesar de não ser um termo propriamente novo. Sua origem está atrelada ao surgimento da agricultura moderna, pois sempre houve pequenos agricultores que cultivavam em suas próprias terras e comercializavam o excedente. $\mathrm{O}$ termo pode estar relacionado a critérios como: tamanho da propriedade, quem administra a terra, tempo de trabalho da família, entre outros. Percebe-se ainda, que esses critérios foram estabelecidos considerando contextos políticos, étnicos, socioeconômicos e ambientais da época (SCHMITZ; MOTA, 2008).

Agricultura familiar é uma forma de produção onde predomina a interação entre gestão e trabalho. São os agricultores familiares que dirigem o processo produtivo, dando ênfase na diversificação e utilizando o trabalho familiar, eventualmente complementado pelo trabalho assalariado (MINISTÉRIO DO DESENVOLVIMENTO AGRÁRIO, 2016).

Nas últimas décadas, tem-se visto uma evolução significativa de modelos de produção agropecuária e de alimentos que atendem a requisitos específicos e diferenciados dos modelos convencionais, como a Agricultura Orgânica (PÉREZ, 2011). Assim, a agricultura orgânica assume maior legitimidade com a crescente preocupação da opinião pública a respeito dos impactos ambientais (SCHULTZ, 2011).

O pequeno produtor cumpre sua função social e ambiental quando consegue produzir sem agredir o meio ambiente. Utiliza os recursos naturais finitos, de forma racional e adequada, visando à manutenção do equilíbrio ecológico e à garantia da saúde, da qualidade de vida e do bem-estar social e econômico dos potenciais consumidores e dos próprios membros da agricultura familiar (MALLMANN et al., 2013).

Analisando a conceituação da agricultura familiar estabelecida pelo poder público, seja Estado seja Governo, observa-se que a primeira conceituação ocorreu por meio da Lei 4.504 (1964), que 
estabeleceu o Estatuto da Terra, em que a propriedade familiar é definida como:

[...] o imóvel que, direta e pessoalmente explorado pelo agricultor e sua família, lhes absorva toda a força de trabalho, garantindo-lhes a subsistência e o progresso social e econômico, com área máxima fixada para cada região e tipo de exploração, e eventualmente trabalhado com a ajuda de terceiros (BRASIL, 1964).

É importante também considerar a conceituação de agricultor familiar segundo o Pronaf, pois somente tem acesso ao Programa de Aquisição de Alimentos os agricultores familiares que dispõem de Declaração de Aptidão do Pronaf (DAP). Em 1995, por meio da Resolução CMN/BACEN nº. 2.191 (1995), entrou em vigência o PRONAF, e naquele momento houve uma primeira conceituação do agricultor familiar. Essa conceituação no âmbito do Pronaf passou por algumas modificações durante essas duas décadas, e hoje estão vigentes critérios relacionados às condições de exploração, residência, tamanho da propriedade, percentual de renda advinda da propriedade e limites, limite de contratação de assalariado (BANCO CENTRAL DO BRASIL, 2016).

Por fim, cabe destacar que neste artigo se compreende a agricultura familiar de maneira ampla e diversificada, conforme explicada por Schmitz e Mota:

O meio rural, cenário em que a agricultura familiar se situa, é hoje, mais do que nunca, espaço constituído por múltiplas atividades agrícolas e não-agrícolas, motivo pelo qual a agricultura familiar é aqui compreendida numa concepção mais ampla incluindo, de forma integral, atividades como a organização de agricultores, produção, beneficiamento, comercialização de produtos agrícolas e não-agrícolas, turismo, pesca, artesanato, etc. (SCHMITZ; MOTA, 2008, p. 438).

\subsection{Cooperativismo}

A cooperação entre as pessoas, devido à necessidade, surgiu desde o início da história da civilização, pois os seres humanos 
perceberam o poder da união, no sentido de realizarem suas atividades e ações com mais rapidez, menores desgastes e custos. Hoje, nota-se que o cooperativismo é uma das formas de associativismo mais desenvolvida e valorizada no Brasil.

O cooperativismo é um movimento, filosofia de vida e modelo socioeconômico, capaz de unir desenvolvimento econômico e bem-estar social. Suas referências fundamentais são a participação democrática, solidariedade, independência e autonomia. O cooperativismo está associado a valores universais e se desenvolve independentemente de território, língua, credo ou nacionalidade (ORGANIZAÇÃO DAS COOPERATIVAS BRASILEIRAS, 2016).

Nesse mesmo sentido, Gawlak (2007) indica que o cooperativismo moderno está ancorado nos seguintes princípios: adesão voluntária e livre; gestão democrática; participação econômica dos associados; autonomia e independência; educação, formação e informação; cooperação entre as cooperativas; e interesse pela comunidade. Esses princípios permitem que o cooperativismo seja uma alternativa socioeconômica que leva ao sucesso do grupo, com equilíbrio e justiça.

Por sua vez, quanto à conceituação da legislação, a Lei nº . 5.764 de 1971 (1971) indica que as sociedades cooperativas podem ser consideradas:

a) Singulares. Para se constituir uma cooperativa singular são necessários no mínimo vinte associados. Caracterizam-se pela prestação direta de serviços aos membros; b) Cooperativas centrais ou federações de cooperativas. São constituídas com no mínimo três singulares, com o objetivo de organizar os serviços econômicos e assistenciais de interesse em comum das filiadas;

c) Confederações de cooperativas. São constituídas de, no mínimo, três federações. Unem-se quando há a necessidade de transcender o âmbito da capacidade das federações.

Assim, nota-se que, nas cooperativas, os cooperados dispõem de liberdade e independência de ações. É essa relação que os mantém na cooperativa. Esse tipo de relação teve início em Rochdale (Inglaterra), em 1844. No Brasil, há registro formal a partir de 1889 (COSTA; AMORIM JUNIOR; SILVA, 2015).

Considerando o contexto do cooperativismo rural a partir dos 
anos de 1970, nota-se que o cooperativismo surgiu como uma alternativa aos produtores, em resposta à competitividade dos mercados. Além disso, as cooperativas propiciaram o fortalecimento da união entre os cooperados, antes isolados em suas propriedades, permitindo o compartilhamento de suas ansiedades, responsabilidades e custos (ANDRADE; ALVES, 2013). Com a maior competitividade e exigência dos consumidores, quem mais sofre no setor rural são os pequenos produtores organizados em pequenas cooperativas e associações. Além disso, são vítimas de descaso por parte das autoridades públicas brasileiras (ROSALEM et al., 2009).

Segundo Nazzari e Zimmermann (2015), o associativismo forte pode congregar estilos mais adaptáveis de cooperação com consequente melhoria da qualidade de vida dos cooperados. O desenvolvimento e a sustentabilidade da propriedade rural familiar proporcionam o fomento com visão orientada para a produção, transformação e comercialização dos produtos. Para tanto, demanda-se assistência técnica e capacitação aos cooperadores, para a gestão econômica e solução dos gargalos da comercialização da produção.

No atual contexto de complexidade e competitividade, as cooperativas, como qualquer organização, devem ser geridas de maneira eficaz e eficiente, buscando, além de criar um ambiente de sinergia entre cooperativa e política pública (PAA), satisfazer seus próprios cooperados. Para isso, torna-se importante a realização de pesquisa junto aos cooperados, visando identificar suas percepções sobre a gestão do empreendimento, bem como, dos programas públicos dos quais os cooperados participam.

\subsection{Políticas Públicas}

Entre os acontecimentos mais marcantes que ocorreram na esfera das políticas públicas para o meio rural brasileiro, a partir da década de 1990, pode-se destacar a criação do Programa Nacional de Fortalecimento da Agricultura Familiar (Pronaf). O surgimento desse programa representou o reconhecimento e a legitimação do Estado em relação às especificidades de uma nova categoria social - os agricultores familiares -, que até então era designada por pequenos produtores, produtores familiares, produtores de baixa renda ou agricultores de subsistência. Ou seja, a política pública foi 
criada em um contexto de pressão dos agricultores familiares, dado seus problemas vivenciados, especialmente quanto à dificuldade de comercialização de seus produtos (SCHNEIDER; CAZELLA; MATTEI, 2009).

Assim, as políticas públicas são criadas para resolver problemas de determinada coletividade. Uma política pública possui dois elementos fundamentais: intencionalidade pública e resposta a um problema público. Em outras palavras, a razão para o estabelecimento de uma política pública é o tratamento ou a resolução de um problema entendido como coletivamente relevante (SECCHI, 2013).

Uma política pública é um conjunto de princípios e critérios e linhas de ação que garantem e permitem a gestão do Estado na solução de problemas nacionais. Considerando que o Estado foi criado para permitir o bem-estar dos indivíduos, as políticas públicas são mecanismos utilizados pelos governos, capazes de garantir que os cidadãos possam buscar a felicidade, de forma equitativa, sem que sejam prejudicados pelas ações de outros indivíduos ou organizações (DIAS; MATOS, 2012). Algumas políticas podem ser consideradas de Estados, enquanto outras são apenas de governos.

Os elementos mais comuns encontrados na definição de políticas públicas, são mencionados por Birkland:

a) a política pública é feita em nome do público; b) a política pública é geralmente feita ou iniciada pelo governo; c) a política pública é interpretada e implementada por atores públicos e privados; d) a política pública é o que o governo pretende fazer; e) a política pública é o que o governo escolhe não fazer (BIRKLAND, 2010, p. 20).

Secchi (2013) explica que na literatura de ciências políticas, os atores são aqueles indivíduos, grupos ou associações que desempenham um papel na arena política. São exemplos de atores individuais os políticos, os burocratas, os magistrados, os formadores de opinião. Os atores coletivos são grupos e organizações que defendem seus interesses comuns. São exemplos de atores coletivos os sindicatos, associações, organizações do terceiro setor etc. Secchi também categorizou os atores em: atores governamentais e atores não governamentais. 
O processo de elaboração de políticas públicas também é conhecido como ciclo de políticas públicas. O ciclo de políticas públicas é um esquema de visualização e interpretação que organiza a vida de uma política pública em fases sequenciais e interdependentes. Nota-se que não há consenso na literatura sobre o número de fases, variando o ciclo da política pública entre quatro e sete fases. Nota-se que há uma tendência por considerar mais racional o modelo de sete fases, por exemplo, o modelo desenvolvido por Secchi (2013). Segundo esse autor, o ciclo de políticas públicas é composto das seguintes fases: 1) identificação do problema, 2) formação da agenda, 3) formulação de alternativas, 4) tomada de decisão, 5) implementação, 6) avaliação, e 7) extinção. Como o foco deste estudo é avaliado, centra-se aqui sua atenção a fase de avaliação.

A avaliação de política pública é um processo de julgamentos deliberados sobre a validade de propostas para a ação pública. Consiste na mensuração, bem como, na análise dos resultados produzidos.

O conceito de avaliação da política pública trata, em termos amplos, da fase ou estágios do processo em que se determina como uma política pública de fato está funcionando na prática, consistindo em avaliar os meios em que são empregados e verificando se os objetivos estão sendo atingidos (HEIDEMANN; SALM, 2014).

A avaliação é uma ferramenta importante, pois permite ao Governo e/ou Estado realizar uma série de ações em função dos resultados obtidos, entre os quais: gerar informações úteis para futuras políticas públicas; prestar contas de seus atos; justificar as ações e explicar seus atos; responder se o recursos, que são escassos, estão produzindo os resultados esperados e da forma mais eficiente possível; identificar as barreiras que impedem o sucesso de um programa; e promover o diálogo entre os vários atores individuais e coletivos envolvidos (DIAS; MATOS, 2012).

Quanto ao uso das avaliações das políticas públicas, os resultados alcançados, envolvem, fundamentalmente, quatro possibilidades: instrumental, conceitual, como instrumento de persuasão e para o esclarecimento (FARIA, 2005).

Nota-se que existem diferentes maneiras de se realizar uma avaliação de políticas públicas, a depender do ator, do foco, do objetivo e da complexidade do programa público. Uma pesquisa de satisfação 
com os beneficiários de determinada política pública é uma forma de avaliação. Obter respostas sobre o êxito ou não de determinada política pública é fundamental para quem se interessa em conhecer a atuação governamental, em avaliar seu grau de eficácia e eficiência e em conhecer os efeitos de sua intervenção, seus acertos e seus erros. A avaliação acadêmica é outro modo de avaliar os programas públicos, sendo mais formal, e enfoca a efetividade das políticas, seus impactos e benefícios, tendo como vantagem uma maior isenção e rigor científico (JANNUZZI, 2011).

Dias e Matos (2012) observaram que há uma tendência geral nas classificações de avaliações na literatura, que, em sua maioria, seguem a tipologia sintetizada na Figura 1, quanto aos tipos de avaliação das políticas públicas. 1) Avaliação interna versus externa. $\mathrm{Na}$ avaliação interna, o processo é realizado pela própria equipe do programa ou por pessoal contratado pelos próprios gestores. A avaliação externa é feita por peritos contratados pela Administração, porém com total autonomia de análise. 2) Avaliação formativa ou somativa. Na avaliação formativa, o foco é fornecer informações para melhorar o objeto da política; é um processo de aprendizagem. O foco da avaliação somativa é levantar informações para decidir se um programa deve continuar, expandir-se ou se, porém, deve terminar. 3) Dependendo do conteúdo da avaliação. É possível distinguir três tipos de avaliações com base nos elementos do programa a ser avaliado: a) avaliação conceitual ou design. Seu objeto é analisar a concepção do programa, isto é, sua racionalidade, coerência e consistência. b) avaliação do processo de implementação ou gestão do programa. Trata-se de examinar a maneira pela qual ele é gerido e executado, isto é, sua implementação. c) avaliação quanto aos impactos e resultados. Trata-se de saber em que medida a política ou o programa alcança os objetivos ou atinge o valor de parâmetros ou critérios definidos e custos disponíveis. 4) Avaliação em relação à aplicação ou execução do programa. A avaliação ex-ante é executada antes de se executar o plano, política ou programa, sendo seu objetivo principal analisar sua adequação às necessidades que o motivam e suas chances de sucesso. Já a avaliação intermediária é executada durante a implementação e objetiva a realização de uma análise crítica dos dados coletados sobre o programa como um todo e a mediação da forma 
como os objetivos estão sendo alcançados. Por fim, a avaliação ex-post é feita ao término do programa, permitindo avaliar o sucesso do programa, o sucesso da estratégia concebida do mesmo, seu grau de flexibilidade, a sua eficácia e a eficiência e a adequação dos mecanismos de gestão e acompanhamento.

Figura 1 - Tipos de avaliação de políticas públicas

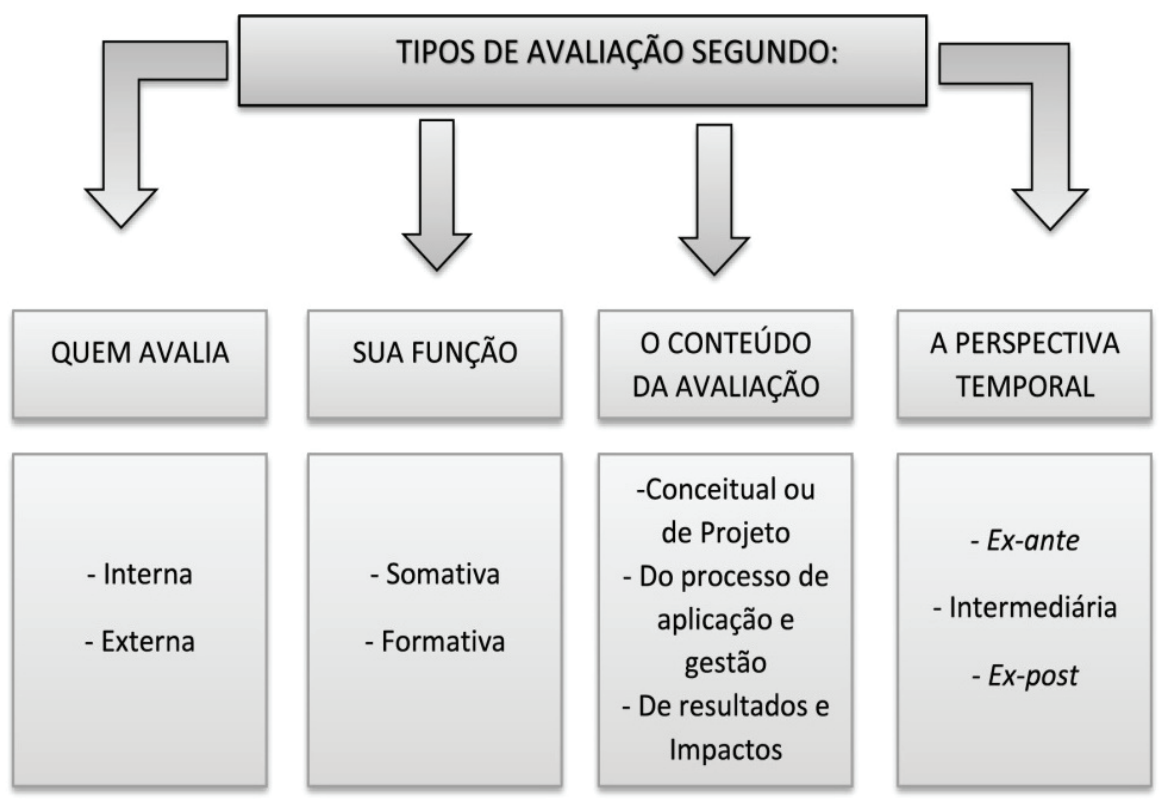

Fonte: Dias e Matos (2012, p. 98).

Jannuzzi (2011) explica que cada tipo de estudo avaliativo requer uma abordagem metodológica e/ou disciplina diferente. A avaliação de processos pode requerer emprego de técnicas variadas de coleta de informações usadas na pesquisa social. As funções de avaliação de políticas públicas, seja interna seja externa, requerem uma força de trabalho altamente treinada, com a gestão orientada para o futuro, bem como, uma excelente capacidade de coleta de informação e de processamento de dados. Elas também exigem a coordenação adequada entre as organizações participantes, para garantir que a pesquisa em curso seja relevante e apropriada. No 
entanto, essas condições são raramente atendidas e os grandes esforços na avaliação de políticas são prejudicados pelas seguintes restrições técnicas e organizacionais: falta de apoio organizacional; falta de experiência em avaliação; percepção estreita do escopo da avaliação; falta de capacidade na coleta de dados (WU et al., 2014).

\subsection{Programa de Aquisição de Alimentos}

O Programa de Aquisição de Alimentos da Agricultura Familiar (PAA) é uma política pública criada pelo Governo Federal, instituído por meio do artigo 19, da Lei no. 10.696, de 2 de julho de 2003, no âmbito do Programa Fome Zero. A Lei no 10.696 foi alterada pela Lei no. 12.512, de 14 de outubro de 2011. Com mais de 11 anos de vigência, o PAA já foi regulamentado por diversos decretos, resoluções e portaria. Desde 4 de julho de 2012 está vigente o Decreto nํ. 7.775 (2012) - apesar das alterações promovidas pelo Decreto nº 8.293, de 12 de agosto de 2014.

O PAA conta com a participação dos entes da Federação, Estados, Distrito Federal e municípios como parceiros executores. Essa política pública, além de contribuir com a segurança alimentar de grupos em riscos, desde 2012, passou também a integrar o eixo Inclusão Produtiva - do Plano Brasil sem Miséria, que tem como objetivo erradicar a pobreza extrema e melhorar as condições de bem-estar da população (MINISTÉRIO DO DESENVOLVIMENTO SOCIAL E COMBATE À FOME, 2016a).

A política pública PAA possui duas finalidades básicas: promover o acesso à alimentação e incentivar a agricultura familiar. Os processos de comercialização por meio do PAA são mais simplificados, sendo dispensada a realização de processos licitatórios para a compra dos produtos da agricultura familiar. O Programa efetua a compra de alimentos produzidos pela agricultura familiar com dispensa de licitação e os destina às pessoas em situação de insegurança alimentar e nutricional e àquelas atendidas pela rede socioassistencial, pelos equipamentos públicos de segurança alimentar e nutricional e pela rede pública e filantrópica de ensino (HESPANHOL, 2013).

São objetivos do Programa de Aquisição de Alimentos, segundo a Lei no 10.696 (2003), editada em 2 de julho: a) incentivar a 
agricultura familiar; b) incentivar o consumo e a valorização dos alimentos produzidos pela agricultura familiar; c) promover o acesso à alimentação em quantidade, qualidade e regularidade necessárias, das pessoas em situação de insegurança alimentar e nutricional; d) promover o abastecimento alimentar, que compreende as compras governamentais de alimentos, incluída a alimentação escolar; e) apoiar a formação de estoques pelas cooperativas e demais organizações formais da agricultura familiar; f) fortalecer circuitos locais e regionais e redes de comercialização.

Por sua vez, o PAA também contribui para a constituição de estoques públicos de alimentos produzidos por agricultores familiares e para a formação de estoques pelas organizações da agricultura familiar. Ademais, o Programa foi idealizado para valorizar a biodiversidade e a produção orgânica e agroecológica de alimentos; incentivar hábitos alimentares saudáveis e estimular o cooperativismo e o associativismo (MINISTÉRIO DO DESENVOLVIMENTO SOCIAL E COMBATE À FOME, 2016b).

Como instrumento de ampliação do público beneficiário, o PAA fomenta ainda o atendimento de famílias extremamente pobres por meio da Busca Ativa, impulsionando, principalmente os municípios, a conhecer suas famílias em situação de maior pobreza, encorajando a sua inserção no Cadastro Único para Programas Sociais - CadÚnico. Essa participação é estimulada, tanto pela inclusão de agricultores cadastrados, quanto pelo aumento de consumidores desses alimentos (MINISTÉRIO DO DESENVOLVIMENTO SOCIAL E COMBATE À FOME, 2016c).

A segurança alimentar tem servido como ferramenta estrutural de inumeráveis programas e projetos de luta contra a fome. Sua estrutura básica compreende quatro componentes centrais - disponibilidade, acesso, estabilidade e consumo (GOMES; ALMEIDA, 2010).

No sentido de atender aos objetivos da Lei de criação do PAA, o programa encontra-se estruturado em seis modalidades. Como já mencionado, o desenvolvimento do Modelo teve como foco a Modalidade CDS que possui as características, conforme o Quadro 1.

Por meio da Plataforma de Indicadores do Governo Federal (PGI, 2015), foi possível constatar que, no período de 2003 a 2014, os volumes de recursos - todas as modalidades do PAA - repas- 
sados à política pública tiveram tendência crescente até 2012, passando de 145 milhões em 2003, para 838 milhões em 2012, depois havendo uma redução em 2013 e 2014. Por sua vez, notou-se que as modalidades do PAA mais utilizadas foram a Compra com Doação Simultânea e o Incentivo à Produção e Consumo do Leite, no período de 2003-2010. Dados do Ministério do Desenvolvimento Social têm demonstrado que a tendência tem sido a mesma para o período de 2011-2014, mantendo a modalidade de Compra com Doação Simultânea (CDS) como aquela que mais recebe recursos do PAA, com um percentual de $66 \%$.

Quadro 1 - Características da Modalidade Compra com Doação Simultânea (CDS)

\begin{tabular}{|c|c|c|c|c|}
\hline Modalidade & Conceito & $\begin{array}{c}\text { Forma de } \\
\operatorname{acesso}^{(1)}\end{array}$ & $\begin{array}{c}\text { Limites } \mathbf{R} \$ \text { / } \\
\text { por ano }\end{array}$ & $\begin{array}{c}\text { Origem do } \\
\text { Recurso }\end{array}$ \\
\hline \multirow[b]{2}{*}{$\begin{array}{c}\text { Compra da } \\
\text { Agricultura } \\
\text { Familiar para } \\
\text { Doação } \\
\text { Simultânea - } \\
\text { CDS }\end{array}$} & \multirow{2}{*}{$\begin{array}{l}\text { A Modalidade Compra com Doação } \\
\text { Simultânea promove a articulação entre a } \\
\text { produção da agricultura familiar e as } \\
\text { demandas locais de suplementação } \\
\text { alimentar, além do desenvolvimento da } \\
\text { economia local. Os produtos adquiridos } \\
\text { dos agricultores familiares são doados às } \\
\text { pessoas em insegurança alimentar, por } \\
\text { meio da rede socioassistencial ou } \\
\text { equipamentos públicos de segurança } \\
\text { alimentar e à rede pública e filantrópica } \\
\text { de ensino. A Compra com Doação } \\
\text { Simultânea-CDS permite a aquisição de } \\
\text { alimentos in natura ou processados, } \\
\text { enriquecendo os cardápios dos } \\
\text { beneficiários consumidores. } \\
\text { fornecimento de produtos orgânicos é } \\
\text { privilegiado, sendo possível incluir até } \\
30 \% \text { a mais do que o valor pago para o } \\
\text { alimento convencional. }\end{array}$} & Individual & $\begin{array}{l}\text { R\$ 6, } 5 \text { mil ou } \\
\text { R\$ } 8 \text { mil (via } \\
\text { organização) }\end{array}$ & \\
\hline & & $\begin{array}{l}\text { Organizações } \\
\text { (cooperativas/ } \\
\text { associações) }\end{array}$ & R\$ 2 milhões ${ }^{(2)}$ & MDS \\
\hline
\end{tabular}

(1) O beneficiário fornecedor poderá participar de mais de uma modalidade e os limites serão independentes entre si. ${ }^{(2)}$ Respeitando os limites por unidade familiar. Fonte: Adaptado do MDS (2015b) 
Dessa forma, considerando que a modalidade do PAA de Compra com Doação Simultânea é a que mais recebe recursos e a que envolve um maior número de agricultores familiares, justifica-se assim o desenvolvimento do Modelo de Avaliação de Satisfação para essa modalidade.

\subsection{Estudos Anteriores sobre o Tema}

Devido à necessidade de verificação dos resultados efetivos dos programas públicos, no intuito de atender às exigências dos cidadãos/clientes, os governos e pesquisadores têm avaliado nos últimos anos diferentes tipos de políticas públicas, desde as mais tradicionais, como saúde e educação, passando até as áreas sociais e políticas do desenvolvimento rural.

Para subsidiar a discussão sobre a avaliação do PAA, utilizou-se do levantamento da produção científica realizado por Nascimento et al. (2015), no período de março e abril de 2015, no qual investigaram a produção científica a respeito do tema durante a última década (2005 a março/2015). O referido levantamento das produções científicas buscou identificar todos os aspectos avaliativos sobre o PAA, que investigaram a gestão da política pública e/ou as percepções de um dos atores do PAA. Dessa forma, destacaram-se como principais resultados positivos do Programa de Aquisição de Alimentos, e que repercutem direta ou indiretamente na percepção de satisfação dos agricultores familiares, fatores como: valorização da agricultura familiar; incentivo a uma alimentação saudável para a população; apoio à sustentabilidade ambiental; melhoria de qualidade de vida dos agricultores familiares; e incentivo ao associativismo. Como fatores susceptíveis de melhorias: apoio à capacitação gerencial das associações e agricultores familiares; melhoria do preço de compra dos alimentos; equilíbrio da distribuição dos recursos do programa aos Estados; falta de conhecimento dos gestores públicos sobre o programa, entre outros.

Nesse sentido, faz-se importante a avaliação do grau de satisfação dos atores participantes das políticas públicas, visando investigar suas percepções e expectativas esperadas e alcançadas, com o programa público. Segundo o Programa de Gespública, do Ministério do Planejamento, Orçamento e Gestão (MPOG) (2013), as 
pesquisas de satisfação são relevantes na obtenção de informações sobre as expectativas, percepções de desempenho e preferências dos participantes de determinados projetos. A satisfação pode ser considerada um sentimento de prazer ou desapontamento, resultante da comparação do desempenho esperado de um produto ou serviço, em relação às expectativas da pessoa (KOTLER, 1998).

\subsection{Indicadores Fundamentais para a Avaliação do Progra- ma de Aquisição de Alimentos}

No processo moderno de avaliação de políticas públicas, um de seus principais objetivos é a verificação da efetividade e transparência dos programas públicos. Como o PAA se trata de uma política pública nacional, optou-se por utilizar, como referência para o desenvolvimento do MAS, o Modelo Lógico do Instituto de Pesquisa Econômica Aplicada (IPEA), no que couber. O IPEA (2010) indica que o modelo lógico busca configurar um desenho do funcionamento do programa, que seja factível em certas circunstâncias, para resolver os problemas identificados. Pode ser a base para um convincente relato do desempenho esperado, ressaltando onde está o problema objeto do programa e como este se qualifica para enfrentá-lo. O modelo lógico pode ser desenvolvido para a implementação de novas políticas públicas, como também para a avaliação de programas públicos em operacionalização. É no último caso que se enquadra a avaliação do PAA, considerando que o programa é operacionalizado desde 2003.

Apresentam-se a seguir os procedimentos para a elaboração de modelo lógico de programas existentes, conforme referência do IPEA, consistindo em três Etapas: Etapa I - coleta e análise das informações; Etapa II - pré-montagem do modelo lógico; Etapa III - validação do modelo lógico. Na sequência, são detalhadas essas etapas e subetapas:

Etapa I - coleta e análise das informações: a) Coleta de documentação; b) entrevistas com integrantes da equipe gerencial; c) sistematização das informações coletadas.

Etapa II - Pré-Montagem do Modelo Lógico: a) Explicação do problema e referências básicas (objetivo, público-alvo e beneficiá- 
rios); b) Estruturação do programa para o alcance de resultados; c) Definição de fatores de contexto.

Etapa III - Validação do Modelo Lógico: a) Checagem dos componentes do modelo lógico; b) Análise de vulnerabilidade.

\section{Modelo proposto}

Esta seção teve como objetivo fundamentar o Modelo proposto. Na primeira subseção (3.1), apresentaram-se as ações realizadas para a fundamentação do Modelo MAS. Já na segunda subseção (3.2) foram detalhadas as três etapas para a aplicação do Modelo.

Considerando que não foram localizados, nem na literatura nem tampouco nos estudos científicos pesquisados, modelos representativos que abordassem diretamente a avaliação de satisfação dos agricultores familiares quanto aos aspectos operacionais e socioeconômicos do PAA, construiu-se uma metodologia, a partir dos elementos apresentados no referencial teórico (Agricultura familiar, políticas públicas, Programa de Aquisição de Alimentos, Cooperativismo e Experiências similares no Brasil), embasada nos pressupostos do Modelo Lógico do IPEA.

\subsection{Fundamentação do Modelo MAS}

Utilizando-se das referências do Modelo Lógico do IPEA, realizaram-se as ações de fundamentação do Modelo MAS, conforme segue.

Etapa I - coleta e análise das informações:

a) Coleta de documentação. Para a construção do MAS, a coleta da documentação foi realizada em sítios governamentais (legislações, decretos e resoluções) e institucionais - CONAB e MDS (histórico do PAA, volume de recursos, modalidades, participação dos produtores, entre outros). Além disso, considerando que também é objetivo do MAS verificar a eficiência da gestão das cooperativas e associações, por meio do Diretor e da contadora, de uma grande cooperativa representativa dos agricultores familiares do oeste do Paraná - a Cooperativa da Agricultura Familiar e Solidária do Oeste do Paraná (COAFASO) - coletou-se informaçoes administrativas e de gestão.

b) Entrevistas com integrantes da equipe gerencial. Essa ação não foi realizada com a equipe gerencial do PAA, considerando que 
a presente avaliação é externa, evitando a participação direta dos formatadores da política pública. No entanto, as lacunas e dúvidas sobre o programa foram sanadas por meio de documentação recolhida; consulta com especialista da área (consulta a um Professor Universitário de Desenvolvimento Rural e Segurança Alimentar); consulta com o Diretor de uma Cooperativa participante do PAA; e consulta com dois técnicos de Assistência Técnica e Extensão Rural, que efetuam trabalhos na região Oeste do Paraná.

c) Sistematização das informações coletadas. As informações coletadas, por meio dos diferentes processos, e relatadas nos capítulos anteriores, permitiram verificar a importância do PAA como política pública para o meio rural.

Etapa II - Pré-Montagem do Modelo Lógico:

a) Explicação do problema e referências básicas (objetivo, público-alvo e beneficiários). O problema cuida em analisar o grau de satisfação dos agricultores familiares quanto a alguns aspectos operacionais e socioeconômicos do PAA. Nesse sentido, o modelo MAS teve como objetivos: conhecer os perfis dos agricultores familiares participantes do PAA; analisar o grau de satisfação desses agricultores em relação aos aspectos operacionais e socioeconômicos do PAA; e analisar o grau de satisfação em relação à gestão da cooperativa ou associação nas quais estão filiados. Assim, o público-alvo do modelo MAS foram os agricultores familiares que participam do PAA, modalidade CDS, por meio das cooperativas ou associações. Os principais beneficiários do PAA são os próprios agricultores familiares e a população em situação de insegurança alimentar.

b) Estruturação do programa para o alcance de resultados. Para alcançar resultados efetivos na aplicação do modelo MAS, primeiramente verificou-se que seria necessário traçar um perfil detalhado desses agricultores familiares participantes do PAA - modalidade Compra com Doação Simultânea. Isso se deve ao fato de a CONAB e os demais órgãos públicos (MDS e MDA) não possuírem dados significativos e detalhados em seus registros. Dessa forma, na Variável I - Caracterização dos Agricultores Familiares participantes do $P A A$ - considerando essa limitação, nesse sentido direcionou-se os indicadores, conforme apresentado no Quadro 2. 
Quadro 2 - Variáveis e categorias de construção dos indicadores do MAS

\begin{tabular}{|c|c|c|}
\hline Variáveis & Categorias & Indicadores \\
\hline $\begin{array}{l}\text { I - Caracte- } \\
\text { rização dos } \\
\text { Agricultores } \\
\text { Familiares } \\
\text { participantes } \\
\text { do PAA }\end{array}$ & $\begin{array}{l}\text { Perfil dos } \\
\text { agricultores } \\
\text { familiares }\end{array}$ & $\begin{array}{l}\text { Dados sobre a atividade rural, propriedade, número de } \\
\text { membros da família } \\
\text { Motivo da participação no PAA } \\
\text { Filiação junto às cooperativas ou associações } \\
\text { Relacionamento com as cooperativas e unidades recebedoras } \\
\text { Início na participação do PAA e quantidade de modalidade } \\
\text { que participam } \\
\text { Predisposição para a produção de orgânicos } \\
\text { Exxito na entrega dos produtos do PAA } \\
\text { Principal dificuldade para participar no PAA } \\
\text { Impactos do PAA sobre a produção e comercialização }\end{array}$ \\
\hline \multirow{5}{*}{$\begin{array}{l}\text { II - Satisfação } \\
\text { dos agriculto- } \\
\text { res familiares } \\
\text { em relação ao } \\
\text { PAA }\end{array}$} & $\begin{array}{l}\text { Informação e } \\
\text { capacitação }\end{array}$ & $\begin{array}{l}\text { Apoio das ATER } \\
\text { Apoio dos órgãos públicos } \\
\text { Apoio pelo operador do PAA }\end{array}$ \\
\hline & $\begin{array}{l}\text { Grupos } \\
\text { prioritários } \\
\text { do PAA }\end{array}$ & $\begin{array}{l}\text { Percepção sobre os grupos prioritários definidos pelo MDS } \\
\text { Percepção sobre a prioridade dada pelo PAA aos produto- } \\
\text { res de orgânicos e mulheres }\end{array}$ \\
\hline & $\begin{array}{l}\text { Documenta- } \\
\text { ção exigida } \\
\text { pelo PAA }\end{array}$ & $\begin{array}{l}\text { Exigências para a DAP } \\
\text { Exigências para o PAA } \\
\text { Condições e obrigações do Termo de compromisso }\end{array}$ \\
\hline & $\begin{array}{l}\text { Questões } \\
\text { operacionais } \\
\text { do PAA }\end{array}$ & $\begin{array}{l}\text { Qualidade dos produtos entregues } \\
\text { Características dos produtos solicitados pela CONAB } \\
\text { Ajuda para o transporte e embalagens }\end{array}$ \\
\hline & $\begin{array}{l}\text { Aspectos } \\
\text { financeiros } \\
\text { do PAA }\end{array}$ & $\begin{array}{l}\text { Preços recebidos pelos produtos } \\
\text { Impacto do PAA sobre a renda } \\
\text { Relação preço recebido com o custo de produção }\end{array}$ \\
\hline \multirow{2}{*}{$\begin{array}{l}\text { II - Satisfação } \\
\text { dos agriculto- } \\
\text { res familiares } \\
\text { em relação ao } \\
\text { PAA }\end{array}$} & $\begin{array}{l}\text { Os efeitos } \\
\text { do PAA na } \\
\text { produção }\end{array}$ & $\begin{array}{l}\text { Efeitos na compra de bens móveis } \\
\text { Efeitos no aumento e diversificação da produção } \\
\text { Efeitos na utilização de novas tecnologias }\end{array}$ \\
\hline & $\begin{array}{l}\text { Os efeitos } \\
\text { sociais do } \\
\text { PAA }\end{array}$ & $\begin{array}{l}\text { Efeitos na compra de bens duráveis } \\
\text { Efeitos na vida escolar dos filhos dos agricultores familiares } \\
\text { Percepção com a segurança alimentar } \\
\text { Percepção sobre a Política Pública PAA }\end{array}$ \\
\hline $\begin{array}{l}\text { III - Satisfação } \\
\text { em relação } \\
\text { à gestão da } \\
\text { cooperativa } \\
\text { ou associação } \\
\text { nas quais estão } \\
\text { filiados }\end{array}$ & $\begin{array}{l}\text { Aspectos da } \\
\text { gestão da } \\
\text { Cooperativa } \\
\text { ou Associa- } \\
\text { ção }\end{array}$ & $\begin{array}{l}\text { Grau de participação da proposta do PAA } \\
\text { Procedimentos dos PAA repassados pela Cooperativa ou } \\
\text { Associação } \\
\text { Apoio operacional da Cooperativa ou Associação } \\
\text { Grau de oportunidade dada aos cooperados } \\
\text { Atendimento e resolução de conflitos dos cooperados } \\
\text { Grau de participação nas assembleias gerais } \\
\text { Estratégias adotadas pela cooperativa ou associação para a } \\
\text { celebração de parcerias } \\
\text { Transparências das informações e canais de reclamações }\end{array}$ \\
\hline
\end{tabular}

Fonte: Elaborado pelos Autores (2016). 
De maneira similar, apresentam-se no Quadro 2 os indicadores indispensáveis para analisar a satisfação dos agricultores familiares referente à Variável II - Satisfação dos agricultores familiares em relação ao PAA e a Variável III - Satisfação em relação à gestão da cooperativa ou associação nas quais estão filiados.

Compreender a percepção dos agricultores sobre as questões operacionais do PAA e o seu grau de satisfação quantos aos resultados socioeconômicos, propiciados pela política pública, é fundamental para redirecionar algumas ações, caso seja necessário. Além disso, considerando que na modalidade de CDS-CONAB os agricultores familiares só podem entregar seus produtos por meio de uma cooperativa, é importante verificar o grau de satisfação dos filiados quanto à gestão da organização, pois conflitos entre cooperativa e filiados podem impactar indiretamente no funcionamento do PAA.

c) Definição de fatores de contexto. Na definição das causas e consequências que podem impactar nos resultados do PAA, é necessário avaliar principalmente as variáveis econômicas e políticas do país, dado que o PAA é uma espécie de mercado institucional, atuando na compra de produtos da agricultura familiar. Em se tratando de um mercado institucional, esse é afetado pela oferta e demanda de produtos, ocasionando, por exemplo, a oscilação dos preços pagos aos produtores. Além disso, considerando que o PAA é uma política de governo, o mesmo pode ser afetado por decisões políticas e orçamentárias, isto é, o governo poderia interpretar o PAA como uma política pública não prioritária.

Etapa III - Validação do Modelo Lógico:

a) Checagem dos componentes do modelo lógico. Nesta ação, considerando que o modelo lógico proposto se trata de uma avaliação externa e de uma pesquisa acadêmica, os componentes do Modelo MAS foram checados pelos próprios pesquisados.

b) Análise de vulnerabilidade. Na construção do modelo lógico, foram observadas as possíveis fragilidades do modelo de avaliação, a fim de eliminá-las. Por conseguinte, optou-se pela supressão da variável ambiental, que constava no esboço inicial do modelo, pois na análise de estudos anteriores foi verificado que as possíveis vulnerabilidades do PAA poderiam estar mais relacionadas às questões operacionais e socioeconômicas. 
O MAS é um modelo de avaliação externa, pois é realizado por pesquisadores que não participaram das fases anteriores da Política Pública. Possui caráter de avaliação formativa, considerando que o foco é fornecer informações para melhorar o objeto da política, contribuindo para o processo de aprendizagem sobre o assunto. O MAS tem como conteúdo de avaliação os impactos e resultados da política pública, pois seu principal objetivo é verificar o grau de satisfação de alguns dos atores participantes do programa. Por fim, o Modelo proposto, em relação à execução do programa, tem característica de avaliação intermediária, dado que ocorrerá durante a implementação, tendo como objetivo a realização de uma análise crítica dos dados coletados a respeito do programa como um todo e a medição da forma como os objetivos estão sendo alcançados. A caracterização do Modelo MAS, em relação ao Modelo de Classificação de Avaliações de Políticas Públicas (DIAS; MATOS, 2012), pode ser visualizada na Figura 2.

Figura 2 - Caracterização dos tipos de avaliação do Modelo MAS

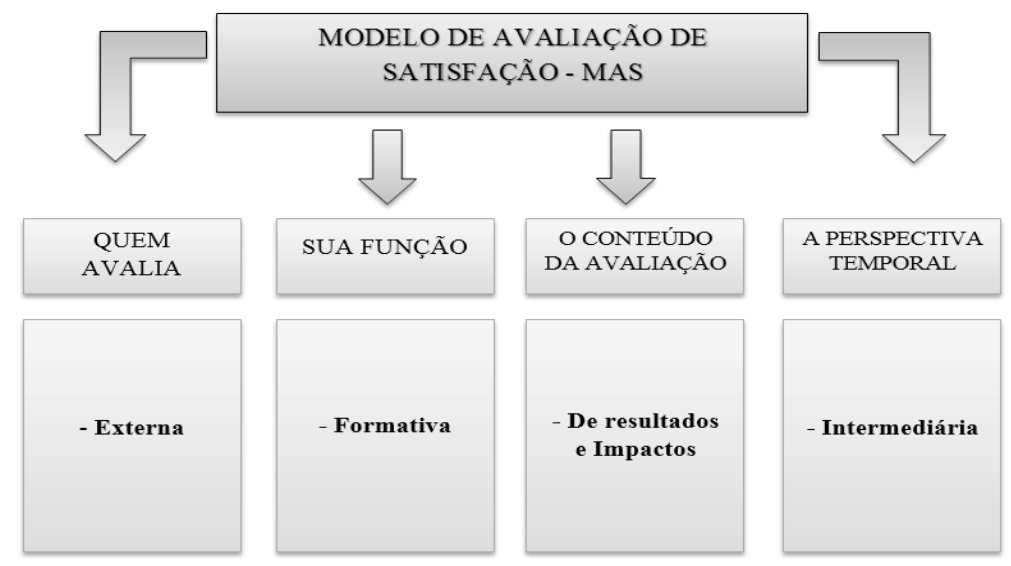

Fonte: Adaptado de Dias e Matos (2012, p. 98).

Dessa forma, o modelo de avaliação externa proposto preencheu uma lacuna existente quanto à análise da satisfação dos agricultores familiares, que envolvessem consistentes aspectos operacionais e socioeconômicos. Por meio do levantamento da produção científica, 
constatou-se que as avaliações externas realizadas se concentraram apenas em realidades locais, não havendo, nesses modelos, a preocupação de uma possível replicação a outras regiões do Brasil.

O modelo foi concebido a partir de três variáveis principais, que pretende identificar a percepção dos agricultores familiares: perfis dos agricultores familiares; grau de satisfação sobre os efeitos do PAA - CDS; grau de satisfação sobre a eficiência da cooperativa ou associação (Figura 3).

Figura 3 - Concepção do Modelo de Avaliação de Satisfação

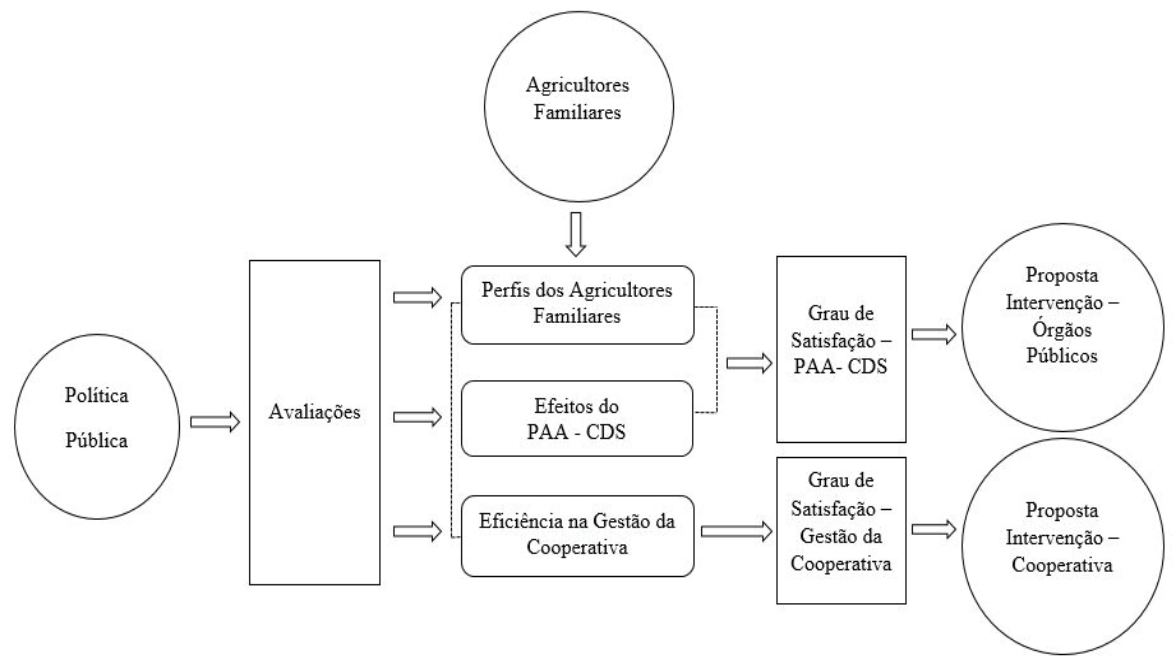

Fonte: Elaborado pelo Autores (2016).

\subsection{Etapas de Aplicação do MAS}

Nesta subseção, são indicadas as três etapas estabelecidas para a aplicação do MAS (Figura 4). 
Figura 4 - Etapas para a aplicação do MAS

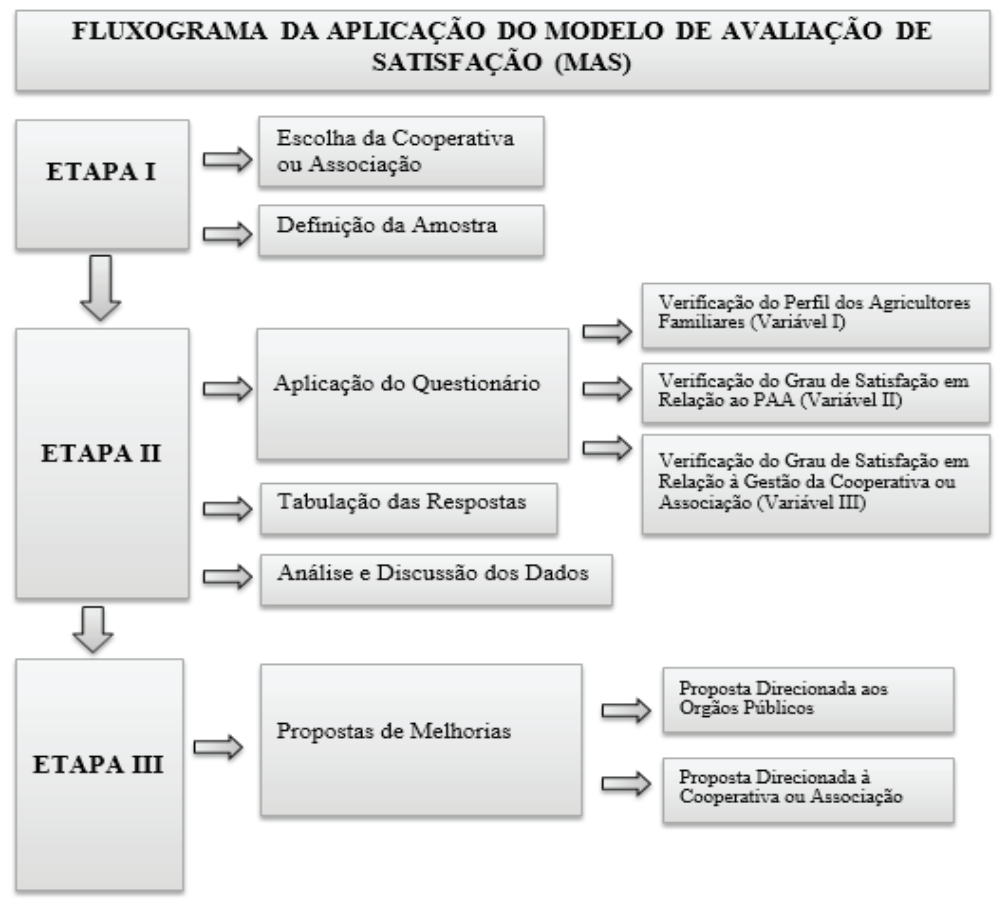

Fonte: Elaborado pelos autores (2016).

Etapa I - Definição da organização onde será aplicado o Modelo de Avaliação da Satisfação (MAS) dos agricultores familiares

Nesta etapa, deve ser selecionada uma Organização (Cooperativa ou Associação) fornecedora de Produtos do PAA, considerando que, na Modalidade de Compra com Doação Simultânea (CDS-CONAB), as entregas dos Produtos só podem ocorrer por meio de uma Organização, ou seja, individualmente é vedado aos agricultores familiares realizarem a entrega dos produtos às unidades recebedoras. Recomenda-se, portanto, incluir na população todos os agricultores familiares que participaram de algum projeto do PAA-CDS, independentemente do ano, no intuito de se alcançar uma população significativa e, assim, permitir uma amostra coerente e válida estatisticamente.

Esse modelo proposto não limita a forma de se alcançar a amostra a ser investigada, devendo o pesquisador analisar as carac- 
terísticas gerais de sua população, região e forma de acessibilidade dos dados, calculando sua amostra segundo o tipo mais apropriado a partir da literatura.

Etapa II - Aplicação do Instrumento de Pesquisa, tabulação e discussão dos resultados dos dados

Para a construção do instrumento, utilizou-se a estrutura composta por questões associadas a uma escala do tipo Likert. De acordo com Malhotra (2001), a escala Likert constitui-se em uma escala de medida com cinco ou sete categorias de respostas que podem variar de "discordo totalmente" a "concordo totalmente". A escala adotada pelo estudo correspondeu a " 0 = Muito Insatisfeito"; " 1 = Insatisfeito"; "2 = Indeciso/Neutro"; "3 = Satisfeito"; " 4 = Muito Satisfeito".

As questões foram subdivididas em três conjuntos de questões: Variável I - Perfil; Variável II - Avaliação do PAA; e Variável III Avaliação da Gestão das Cooperativas. A escala de pontos foi escolhida devido à possibilidade de sua transformação em escala somada e por permitir a obtenção de escores de pontuação. $\mathrm{O}$ instrumento foi desenvolvido a partir dos indicadores elencados no Quadro 2.

A Variável I do modelo de avaliação (Quadro 3) é composta de questões que não foram contempladas nas bases de dados dos órgãos executores da política pública. Dessa forma, esses conjuntos de indagações permitem, junto aos demais conjuntos, entender quais são as possíveis potencialidades e gargalos do programa.

Portanto, os dados relativos às questões da Variável I - Caracterização dos agricultores familiares participantes do PAA (questões 01 a 18) caracterizam os agricultores familiares, em relação aos seguintes indicadores: dados sobre a atividade rural, a propriedade, o número de membros da família; motivo da participação no PAA; filiação junto às cooperativas; relacionamento com as cooperativas e unidades recebedoras; início da participação no PAA e quantidade de modalidades que participam; predisposição para a produção de orgânicos; êxito na entrega dos produtos do PAA; principal dificuldade para participar no PAA; e impactos do PAA sobre a produção e a comercialização. Dessa forma, após realizar esse levantamento das informações dos entrevistados, é possível traçar um perfil predominante dos agricultores familiares, possibilitando o direcionamento de ações ao público alvo predominante ou a pequenos grupos não contemplados na política pública. 
Quadro 3 - Variável I - Caracterização dos agricultores familiares participantes do PAA

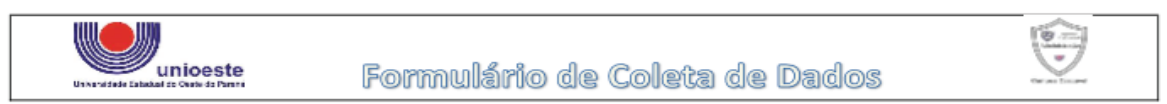

\section{VARIÁVEL I}

CARACTERIZAÇÃO DOS AGRICULTORES FAMILIARES PARTICIPANTES DO PAA

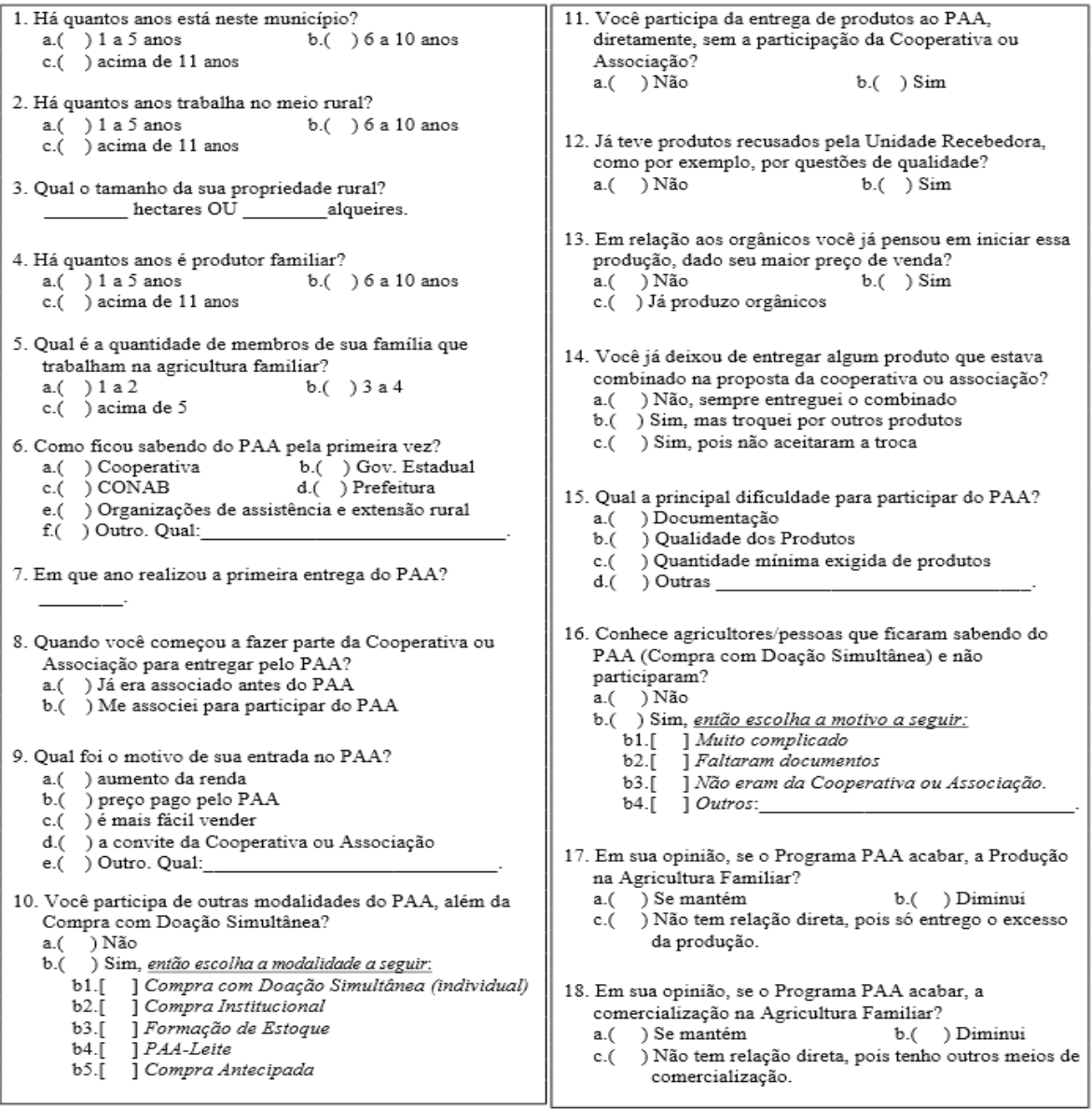

Fonte: Elaborado pelos autores (2016). 


\section{Quadro 4 - Variável II - Grau de satisfação em relação ao PAA}

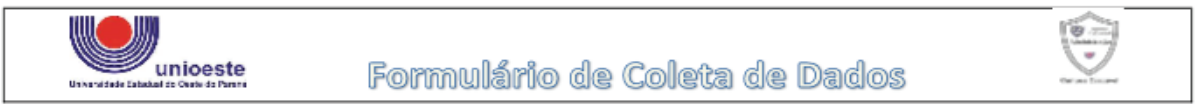

\begin{tabular}{|c|c|c|c|c|c|c|}
\hline & $\begin{array}{c}\text { VARIÁVEL II } \\
\text { GRAU DE SATISFAČ̃̃ EM RELAČ̃õo AO PROGRAMA DE } \\
\text { AQUISIC̣ÃO DE ALIMENTOS (PAA) }\end{array}$ & 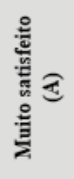 & 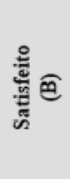 & 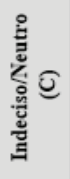 & 莺 & 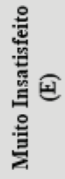 \\
\hline \multicolumn{2}{|r|}{ Em relação às informações/capacitações recebidas indique o grau de satisfação: } & \multicolumn{5}{|c|}{ Assinalar somente uma alternativa } \\
\hline 19. & Com as organizações de assistência e extensão rural. & & & & & \\
\hline 20. & Com o apoio recebido pelo governo (prefeitura, Estado ou CONAB). & & & & & \\
\hline 21. & $\begin{array}{l}\text { Com o PAA, considerando as explicações/treinamento para o entendimento } \\
\text { sobre a Modalidade de Compra com Doação Simultânea. }\end{array}$ & & & & & \\
\hline \multicolumn{2}{|r|}{ Em relação aos grupos prioritários do PAA indique o grau de satisfação: } & \multicolumn{5}{|c|}{ Assinalar somente uma alternativa } \\
\hline 22. & $\begin{array}{l}\text { Com os grupos prioritários definidos pelo MDS (CadÚnico; assentados; } \\
\text { indigenas, quilombolas e comunidades tradicionais; mulheres; e produtos } \\
\text { orgânicos ou agroecológicos). }\end{array}$ & & & & & \\
\hline 23. & $\begin{array}{l}\text { Com o percentual de } 40 \% \text { de mulheres e } 5 \% \text { de orgânicos, como obrigatórios } \\
\text { na Compra com Doação Simultânea. }\end{array}$ & & & & & \\
\hline \multicolumn{2}{|r|}{ Em relação às documentações exigidas pelo PAA indique o grau de satisfação: } & \multicolumn{5}{|c|}{ Assinalar somente uma alternativa } \\
\hline 24. & Com as exigências para a obtenção da DAP. & & & & & \\
\hline 25. & Com o PAA, considerando as documentações exigidas ( $\mathrm{CPF}$ e DAP). & & & & & \\
\hline 26. & Com as condições e obrigações estabelecidas no termo de compromisso. & & & & & \\
\hline \multicolumn{2}{|r|}{ Em relação às questões operacionais do PAA indique o grau de satisfação: } & \multicolumn{5}{|c|}{ Assinalar somente uma alternativa } \\
\hline 27. & $\begin{array}{l}\text { Com os critérios de qualidade estabelecidos, no momento da entrega dos } \\
\text { produtos. }\end{array}$ & & & & & \\
\hline 28. & $\begin{array}{l}\text { Com os produtos solicitados para compor a proposta à CONAB, refletindo as } \\
\text { caracteristicas da região. }\end{array}$ & & & & & \\
\hline 29. & $\begin{array}{l}\text { Com relação à embalagem dos produtos, pois recebo ajuda da prefeitura ou da } \\
\text { CONAB. }\end{array}$ & & & & & \\
\hline 30. & $\begin{array}{l}\text { Com relação ao transporte do produto, pois recebo ajuda da prefeitura ou da } \\
\text { CONAB. }\end{array}$ & & & & & \\
\hline \multicolumn{2}{|r|}{ Em relação aos aspectos financeiros do PAA indique o grau de satisfação: } & \multicolumn{5}{|c|}{ Assinalar somente uma alternativa } \\
\hline 31. & Com os preços pagos por meus produtos pelo PAA. & & & & & \\
\hline 32. & Com o PAA, pois permitiu o aumento de minha renda. & & & & & \\
\hline 33. & $\begin{array}{l}\text { Com o PAA, pois o preço pago por meus produtos me permite cobrir os custos } \\
\text { de produção. }\end{array}$ & & & & & \\
\hline \multicolumn{2}{|r|}{ Em relacão aos efeitos na produção indique o grau de satisfacão: } & \multicolumn{5}{|c|}{ Assinalar somente uma alternativa } \\
\hline 34. & $\begin{array}{l}\text { Com o PAA, pois me ajudou na compra de bens móveis como carro, moto, } \\
\text { caminhão, trator, roçadeira ou arados. }\end{array}$ & & & & & \\
\hline 35. & Com o PAA, pois com o programa passei a produzir novos produtos. & & & & & \\
\hline 36. & Ao PAA, pois com o Programa aumentei minha área de produção. & & & & & \\
\hline 37. & $\begin{array}{l}\text { Com o PAA, pois passei a utilizar novas tecnologias, como irrigação, } \\
\text { máquinas/implementos ou agricultura orgânica. }\end{array}$ & & & & & \\
\hline \multicolumn{2}{|r|}{ Em relação aos efeitos sociais do PAA indique o grau de satisfacão: } & \multicolumn{5}{|c|}{ Assinalar somente uma alternativa } \\
\hline 38. & $\begin{array}{l}\text { Com o PAA, pois me ajudou na compra de bens duráveis como geladeira, } \\
\text { celular, televisão, computador ou antena parabólica. }\end{array}$ & & & & & \\
\hline 39. & $\begin{array}{l}\text { Somente responder se tiver filhos em idade escolar (até } 18 \text { anos) } \\
\text { Com o PAA, pois me ajudou para que meus filhos continuassem na escola ou } \\
\text { que voltassem a estudar. }\end{array}$ & & & & & \\
\hline 40. & $\begin{array}{l}\text { Com o PAA, pois mesmo fornecendo para o Programa, não deixei de consumir } \\
\text { nenhum produto para vender para o PAA. }\end{array}$ & & & & & \\
\hline 41. & $\begin{array}{l}\text { Com o funcionamento do PAA como política pública de ajuda ao agricultor } \\
\text { familiar. }\end{array}$ & & & & & \\
\hline
\end{tabular}

Fonte: Elaborado pelos autores (2016). 
Na Variável II do modelo de avaliação (Quadro 4), (questões 19 a 41), o foco é verificar o grau de satisfação dos agricultores familiares, considerando as diversas dimensões da Política Pública, para avaliar indicadores provenientes das seguintes categorias: informação e capacitação; grupos prioritários do PAA; documentação exigida pelo PAA; questões operacionais do PAA; aspectos financeiros do PAA; os efeitos do PAA na produção; os efeitos sociais do PAA.

Após colher os dados referentes à Variável II, os dados deverão ser tabulados utilizando o Quadro 5, onde as questões são calculadas, multiplicando-se o número de vezes de cada resposta (a) pela respectiva pontuação (pesos) a ela atribuída (b). Todos esses resultados são somados (c) e, em seguida, divididos pelo número de questões relacionadas à satisfação dos agricultores familiares (d), conforme a proposta metodológica apresentada por Bertolini, Rojo e Lezana (2012).

Quadro 5 - Alocação de Pesos e Elaboração do Grau de Satisfação dos Agricultores Familiares

\begin{tabular}{|l|l|l|}
\hline (a) №. Respostas & (b) Pesos & (a X b) Resultado \\
\hline A & 4 & \\
B & 3 & \\
C & 2 & \\
D & 1 & \\
E & 0 & \\
\hline (c) Soma dos Resultados & \\
(d) №. de questões & \\
(e = c / d) Resultado & \\
\hline
\end{tabular}

Fonte: Adaptado de Bertolini, Rojo e Lezana (2004, p. 578).

Para viabilizar os cálculos de mensuração dos indicadores dessa Variável, logo após é utilizada a Classificação do Grau de Satisfação em Relação ao PAA-CDS (Quadro 6), definida a partir dos resultados das Escalas Likert, as quais os entrevistados indicaram seu grau de concordância ou discordância a declarações relativas ao tema. As 
escalas de classificação obedecem a intervalos de 0,7 pontos e são coloridas para facilitar a visualização dos resultados de acordo com a pontuação: entre 3,3 e 4,0, verde; entre 2,5 e 3,2, azul; entre 1,7 e 2,4, amarelo; entre 0,9 e 1,6, laranja; e até 0,8, vermelho. Portanto, o índice que será encontrado permitirá concluir o grau exato de satisfação dos agricultores familiares em relação ao PAA.

Quadro 6 - Classificação do Grau de Satisfação em Relação ao PAA-CDS

\begin{tabular}{|l|l|}
\hline Grau de satisfação em relação ao PAA & Valores \\
\hline A) Está altamente satisfeito & Entre 3,3 e 4,0 \\
\hline B) Está satisfeito & Entre 2,5 e 3,2 \\
\hline C) Está indeciso sobre os efeitos do PAA & Entre 1,7 e 2,4 \\
\hline D) Está insatisfeito & Entre 0,9 e 1,6 \\
\hline E) Está altamente insatisfeito & Até 0,8 \\
\hline
\end{tabular}

Fonte: Adaptado de Brandalise (2008, p. 192)

Na Variável III do modelo de avaliação (Quadro 7), (Questões 42 a 51), o foco é verificar o grau de satisfação dos agricultores familiares em relação à forma da gestão da Cooperativa, por meio dos seguintes indicadores: grau de participação da proposta do PAA; procedimentos dos PAA repassados pela Cooperativa ou Associação; apoio operacional da Cooperativa ou Associação; grau de oportunidade dada aos cooperados; atendimento e resolução de conflitos dos cooperados; grau de participação nas assembleias gerais; estratégias adotadas pela cooperativa ou associação para celebração de parcerias; e transparências das informações e dos canais de reclamações.

Após a aplicação do instrumento, os dados deverão ser tabulados utilizando o Quadro 5, de Bertolini, Rojo e Lezana (2012) onde as questões são calculadas, multiplicando-se o número de vezes de cada resposta (a) pela respectiva pontuação (pesos) a ela atribuída (b). 
Quadro 7 - Variável III - Grau de satisfação em relação à gestão da Cooperativa

\begin{tabular}{|c|c|c|c|c|c|c|}
\hline & $\begin{array}{l}\text { VARIÁVEL III } \\
\text { GRAU DE SATISFAC̣̃O EM RELAC̣ÃO ÀS ORGANIZAÇÕES } \\
\text { FORNECEDORAS DO PAA } \\
\text { (COOPERATIVAS OU OUTRAS ASSOCIAÇÕES) }\end{array}$ & 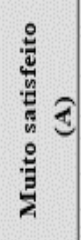 & 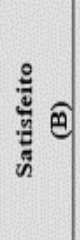 & 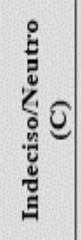 & 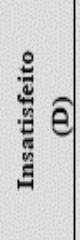 & 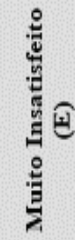 \\
\hline \multicolumn{2}{|r|}{$\begin{array}{l}\text { Em relação aos aspectos de gestão da Cooperativa ou Associação indique o } \\
\text { grau de satisfação: }\end{array}$} & \multicolumn{5}{|c|}{ Assinalar somente uma alternativa } \\
\hline 42. & $\begin{array}{l}\text { Com o nível de sua participação na elaboração da proposta do PAA pela } \\
\text { Cooperativa ou Associação. }\end{array}$ & & & & & \\
\hline 43. & $\begin{array}{l}\text { Com a assistência da Cooperativa ou Associação sobre os procedimentos } \\
\text { do PAA. }\end{array}$ & & & & & \\
\hline 44. & $\begin{array}{l}\text { Com o apoio operacional da Cooperativa ou Associação (ajuda para } \\
\text { embalagens, transporte e certificação de orgânicos). }\end{array}$ & & & & & \\
\hline 45 . & $\begin{array}{l}\text { Com as oportunidades dadas pela Cooperativa ou Associação para a } \\
\text { participação de todos os cooperados. }\end{array}$ & & & & & \\
\hline 46. & Com a forma como os diretores/as dialogam e atendem os associados/as & & & & & \\
\hline 47. & $\begin{array}{l}\text { Com a forma de participação nas Assembleias Gerais da Cooperativa ou } \\
\text { Associação. }\end{array}$ & & & & & \\
\hline 48. & $\begin{array}{l}\text { Com as formas adotadas pelos diretores da Cooperativa ou Associação para } \\
\text { resolver os conflitos entre a cooperativa ou Associação e os filiados }\end{array}$ & & & & & \\
\hline 49. & $\begin{array}{l}\text { Com as estratégias da Cooperativa ou Associação para alcançar novas } \\
\text { parcerias. }\end{array}$ & & & & & \\
\hline 50. & $\begin{array}{l}\text { Com a transparência das informações da Cooperativa ou Associação aos } \\
\text { filiados. }\end{array}$ & & & & & \\
\hline 51. & Com os canais de reclamações existentes. & & & & & \\
\hline
\end{tabular}

Fonte: Elaborado pelos autores (2016).

Para os cálculos de mensuração dos indicadores da Variável III, utiliza-se a Classificação do Grau de Satisfação em relação à gestão da cooperativa (Quadro 8). Portanto, o índice alcançado (entre 0,0 e 4,0), permite concluir o intervalo exato da satisfação dos agricultores familiares. 
Quadro 8 - Classificação do Grau de Satisfação em Relação à Gestão da Cooperativa

\begin{tabular}{|l|l|}
\hline $\begin{array}{l}\text { Grau de satisfação em relação à Gestão da Coope- } \\
\text { rativa }\end{array}$ & Valores \\
\hline A) Está altamente satisfeito & Entre 3,3 e 4,0 \\
\hline B) Está satisfeito & Entre 2,5 e 3,2 \\
\hline $\begin{array}{l}\text { C) Está indeciso sobre a eficiência da Gestão da } \\
\text { Cooperativa }\end{array}$ & Entre 1,7 e 2,4 \\
\hline D) Está insatisfeito & Entre 0,9 e 1,6 \\
\hline E) Está altamente insatisfeito & Até 0,8 \\
\hline
\end{tabular}

Fonte: Adaptado de Brandalise (2008, p. 192)

No intuito de avaliar novas percepções e grau de satisfação dos agricultores familiares, recomenda-se a realização de possíveis cruzamentos (análise bidimensional) entre algumas questões das Variáveis I, II e III, visando verificar se existiriam associações entre o perfil dos entrevistados e possíveis inferências sobre os comportamentos.

Nessa Etapa II, a apresentação dos dados para cada variável deve ser discutida junto aos resultados alcançados, evidenciando os possíveis efeitos negativos e positivos do PAA-CDS, segundo a percepção e satisfação dos agricultores familiares, bem como, de seus feedbacks referentes à forma de gestão da Cooperativa.

\section{Etapa III - Proposta de Intervenção na Política Pública}

Esta etapa consiste na realização de propostas de melhorias ou de intervenção. A primeira proposição de melhoria na política pública do PAA é direcionada aos órgãos públicos competentes (neste momento - MDS e CONAB), com base no grau de satisfação dos fornecedores dos produtos desse programa - agricultores familiares -, no sentido de atenuar possíveis debilidades do PAA.

A segunda proposta de melhoria é orientada aos diretores das Cooperativas e Associações, apresentando-lhes possíveis alternativas para minimizar as prováveis insatisfações dos cooperados, em relação à forma de gestão da organização.

As proposições de melhores devem ser focadas principalmente aos indicadores que receberam notas ruins - "Insatisfeito" e "Muito Insatisfeito". 


\section{Avaliação do modelo proposto}

Pelo fato do MAS ser composto por uma ampla gama de indicadores, o Modelo pode ser uma alternativa de monitoramento e avaliação da política pública, uma vez que pode ser aplicado a várias regiões do país e, a partir dessas conclusões, oportunizar ajustes mais acertados ao programa.

Nesse sentido, o Modelo atua como ferramenta de avaliação de desempenho da política pública PAA, contribuindo para responder à principal pergunta, fato gerador dos programas: a política pública tem solucionado um problema? Considerando a complexidade da avaliação das políticas públicas e o processo cognitivo de cada ator do processo (DIAS; MATOS, 2012; SECCHI, 2013; HEIDEMANN; SALM, 2014), o Modelo MAS não tem a pretensão de ser uma ferramenta única nesse processo avaliativo, mas, sim, somar-se às outras informações, indicadores e sistemas, permitindo aos órgãos públicos um volume maior de informações, que facilite aos gestores a tomada de decisão.

A aplicação dessa metodologia permite ganhos sociais e organizacionais. Sociais porque permite detectar a satisfação de um dos atores participantes do PAA. Agricultores familiares satisfeitos significam alimentos em volumes suficientes para atender às pessoas em condições de insegurança alimentar. Ganhos organizacionais porque possibilita aos gestores das cooperativas ou associações obterem feedback dos filiados, permitindo ajustes operacionais e de atendimento, de acordo com os princípios do cooperativismo. Por conseguinte, contribui para que as cooperativas ou associações sejam, como indica Gawlak (2007), empreendimentos cooperativos em sua essência e uma alternativa socioeconômica que leva ao sucesso do grupo, com equilíbrio e justiça.

O Modelo MAS possui ainda potencial de reaplicação, podendo ser inspirador para outras avaliações de políticas públicas do meio rural, por exemplo o PNAE, desde que seja adaptado segundo suas legislações e perfil dos agricultores participantes.

De maneira geral, o Modelo proposto alcançou seu objetivo principal, uma vez que na consolidação e cálculo das respostas (Quadros 6 e 8) é possível constatar o grau de satisfação dos agricultores familiares de maneira objetiva e conclusiva e, por meio de 
análises unidimensional e bidimensional, é possível inferir pontos fortes e debilidades em relação ao PAA-CDS e à gestão das cooperativas e associações.

Um dos pontos fortes do Modelo é a padronização para o cálculo geral do Grau de Satisfação. Uma vez que o pesquisador tabule as respostas dos formulários de pesquisa aplicados, basta seguir a sequência de três etapas do Modelo MAS, que se alcança o resultado geral, sem margem para subjetividade nos cálculos. Quanto à interpretação das questões de maneira individual, há certo grau de subjetividade na análise, pois dependerá do contexto e da experiência do pesquisador. Outra vantagem do Modelo é que, por meio das correlações bidimensionais, é possível solucionar problemas que estejam diretamente relacionados, evitando a implementação de ajustes apenas paliativos, que logo permitiriam que os problemas ressurgissem.

Quanto à coleta dos dados, é possível que haja certa dificuldade, pois os agricultores familiares estão bastante dispersos territorialmente e isso dificulta a aplicação dos questionários, impactando em maior tempo e custos. No entanto, um planejamento prévio pode facilitar a aplicação dos instrumentos de pesquisa. Assim, recomenda-se um alinhamento com a Cooperativa ou Associação onde será aplicado o Modelo, no intuito de realizar a coleta de dados em Eventos que reúnam os agricultores, como capacitação, grandes feiras ou assembleias gerais. Por sua vez, destaca-se a facilidade da tabulação dos dados.

Outra limitação observada no instrumento de pesquisa pode se tratar dos poucos indicadores sociais estabelecidos na Variável I do questionário. Indicadores envolvendo, por exemplo, dados de escolaridade e renda, talvez permitiriam cruzamentos mais ricos nas análises do tipo bidimensional.

\section{CoNSIDERAÇões FINAIS ${ }^{1}$}

O objetivo geral deste artigo foi o de propor um modelo de avaliação da política pública (PAA), modalidade Compra com

O modelo aqui apresentado foi testado em uma Cooperativa da Região Oeste do Paraná, e o detalhamento dessa aplicação pode ser verificado no artigo publicado na Revista Pensamento Contemporâneo em Administração - RPCA | Rio de Janeiro, v. 11, n. 2 , p. 82-107, abr./jun., 2017. 
Doação Simultânea (CDS), capaz de detectar o grau de satisfação dos agricultores familiares, em relação aos aspectos operacionais e socioeconômicos do programa público.

O Modelo de Avaliação de Satisfação (MAS) dos agricultores familiares, aqui proposto, foi desenvolvido a partir de três pilares principais: referencial teórico, estudos científicos anteriores e legislações pertinentes ao PAA. Após a consolidação dessas informações e com o Modelo Lógico do IPEA como referência, verificou-se quais deveriam ser os elementos fundamentais para a avaliação do programa público, sob a percepção de um de seus principais atores, os agricultores familiares.

Portanto, a questão de pesquisa foi objetivamente respondida, pois por meio do desenvolvimento do MAS foi possível demonstrar a viabilidade de uma metodologia para a avaliação do grau de satisfação dos agricultores familiares.

A presente pesquisa cumpriu também com suas expectativas sociais e operacionais, uma vez que o Modelo desenvolvido permitirá a coleta de informações do PAA de forma padronizada e podendo ser aplicado em todas as regiões do Brasil, possibilitando ajustes operacionais e socioeconômicos pelos órgãos públicos e cooperativas, gerando benefícios para os atores do PAA, bem como para as comunidades locais.

Pretende-se, com o Modelo MAS, preencher uma lacuna na literatura, considerando escassos os estudos direcionados para avaliar políticas públicas do meio rural. Notou-se que esses estudos estavam limitados a regiões ou contextos bastante específicos. Por meio desta pesquisa, verificou-se que as políticas públicas do meio rural são raramente avaliadas de maneira abrangente. De fato, não foram encontradas, nas bases de dados públicos, informações significativas que pudessem contribuir, de modo construtivo, com a elaboração da metodologia aqui proposta. Essa escassez de informações dificulta a tomada de decisão e melhoria efetiva dos gargalos que poderiam ser identificados. Como contribuição, também se espera que esse Modelo possa ser reaplicado, com as devidas adaptações, a outras políticas públicas do meio rural.

Uma limitação desta pesquisa foi o fato de não se ter encontrado um modelo de avaliação específico de políticas públicas do meio 
rural, para que servisse de referência. Dessa forma, utilizou-se como referência, para a construção do MAS, o Modelo Lógico do IPEA, que, apesar de ser um dos mais abrangentes, não pôde ser utilizado em sua plenitude, dado a especificidade das políticas públicas rurais. Como proposta para futuras pesquisas, sugere a aplicação do Modelo aqui proposto numa grande cooperativa ou associação de agricultores familiares, no intuito de comprovar seu real grau de efetividade. Outra pesquisa poderia relacionar a Variável Ambiental como o Programa de Aquisição de Alimentos, uma vez que há escassos estudos com essa abordagem. Esse estudo poderia verificar, por exemplo, se as tecnologias surgidas a partir do PAA possuem realmente um caráter mais respeituoso com o meio ambiente.

\section{REFERÊNCIAS}

ANDRADE, M. C.; ALVES, D. C. Cooperativismo e agricultura familiar: um estudo de caso. RAIMED - Revista de Administração IMED, v. 3, n. 3, p. 194-208, 2013.

BACEN - Banco Central do Brasil. FAQ - Programa Nacional de Fortalecimento da Agricultura Familiar, 2016. Disponível em: <http://www.bcb.gov.br/?PRONAFFAQ>. Acesso em 12 set. 2016.

BERTOLINI, G. R. F.; ROJO, C. A.; LEZANA, A. G. R. Modelo de análise de investimentos para fabricação de produtos ecologicamente corretos. Gest. Prod. São Carlos, v. 19, n. 3, p. 575-588, 2012.

BIRKLAND, T. A. An introduction to the policy process: theories, concepts and models of public policy making, 3. ed. New York: M. E. Sharp, 2010.

BRANDALISE, L. T. A percepção do consumidor na análise do ciclo de vida do produto: um modelo de apoio à gestão empresarial. Cascavel: EDUNIOESTE, 2008.

BRASIL. Lei n. 5.764, de 16 de dezembro de 1971. Define a Política Nacional de Cooperativismo, institui o regime jurídico das sociedades cooperativas. Diário Oficial da República Federativa do Brasil. Brasília, 1971. Disponível em: <http://www.planalto.gov.br/ccivil_03/ leis/L5764.htm>. Acesso em 16 ago. 2016.

Lei n. 4.504, de 30 de novembro de 1964. Dispõe sobre o estatuto da terra. Diário Oficial da República Federativa do Brasil. Brasília, 1964. Disponível em: <http://www.planalto.gov.br/ccivil_03/leis/L4504.htm>. Acesso em 18 ago. 2016.

Decreto n. ${ }^{\circ}$ 1.946, de 28 de junho de 1996. Cria o Programa Nacional de Fortalecimento da Agricultura Familiar - PRONAF. Diário Oficial da República Federativa do Brasil. Brasília, 1996. Disponível em: <http://www.planalto.gov.br/ccivil_03/decreto/D1946. htm>. Acesso em: 10 jul. 2017.

. Lei no․ 10.696, de 2 de julho de 2003. Dispõe sobre a repactuação e o alongamento de dívidas oriundas de operações de crédito rural e dá outras providências. Diário Oficial 
da República Federativa do Brasil. Brasília, 2003. Disponível em: ๑http://www.planalto.gov. br/ccivil_03/leis/2003/110.696.htm๑. Acesso em 8 de maio 2016.

. Decreto n⿳. 7.775, de 2 de julho de 2012. Regulamenta o art. 19 da Lei no. 10.696, de 2 de julho de 2003, que institui o Programa de Aquisição de Alimentos. Brasília. Diário Oficial da República Federativa do Brasil. Brasília, 2012. Disponível em: <http://www.planalto.gov. br/ccivil_03/_ato2011-2014/2012/Decreto/D7775.htm>. Acesso em: 13 de maio 2016.

CARNEIRO, M. J.; MALUF, R. S. (Orgs.). Para além da produção: multifuncionalidade e agricultura familiar. (Introdução). Rio de Janeiro: Mauad, 2003.

CONAB - Companhia Nacional de Abastecimento. Agricultura e abastecimento alimentar: políticas públicas e mercado agrícola. Brasília: CONAB, 2009.

Modalidades do PAA, 2016. Disponível em: <http://www.mds.gov.br/segurancaalimentar/aquisicao-e-comercializacao-da-agricultura-familiar/entenda-o-paa/modalidades-1/ modalidades>. Acesso em jul. 2016.

COSTA, B. A. L.; AMORIM JUNIOR, P. C. G.; SILVA, M. G. As Cooperativas de Agricultura Familiar e o Mercado de Compras Governamentais em Minas Gerais. RESR, v. 53, n. 1, p. 109-126, jan./mar. 2015.

DIAS, R.; MATOS, FERNANDA. Políticas públicas: princípios, propósitos e processos. São Paulo: Atlas, 2012.

FARIA, C. A. P. A política da avaliação de políticas públicas. Revista Brasileira de Ciências Sociais, v. 20, n. 50, p. 97-169, 2005.

GAWLAK, A. Cooperativismo: primeiras lições (3. ed.). Brasília: Sescoop, 2007. Disponível em: <http://www.ocbmt.coop.br/TNX/storage/webdisco/2009/12/28/outros/f2acdd6df5f27518fd2c908db92a1275.pdf>. Acesso em 12 set. 2016.

GOMES JR, N. N.; ALMEIDA FILHO, N. Segurança alimentar e nutricional como princípio ético social de orientação de políticas públicas nacionais. In: ALMEIDA FILHO, N. A.; RAMOS, P. (Orgs.). Segurança alimentar e desenvolvimento territorial. Campinas: Editora Alínea, 2010.

GRISA, C.; SCHNEIDER, S. Três gerações de políticas públicas para a agricultura familiar e formas de interação entre sociedade e estado no Brasil. RESR, v. 52, n. 1, p. 125-146, 2014.

HEIDEMANN, F. G.; SALM, J. F. (Orgs.). Políticas públicas e desenvolvimento, 3. ed. Brasília: Editora Universidade de Brasília, 2014.

HESPANHOL, R. A. M. Programa de Aquisição de Alimentos: limites e potencialidades de políticas de segurança alimentar para a agricultura familiar. Soc. \& Nat., v. 25, n. 3, p. $469-$ 483, set./dez. 2013.

IBGE - Instituto Brasileiro de Geografia e Estatística. Censo Agricultura Familiar, 2006. Disponível em: <http://www.ibge.gov.br/home/estatistica/economia/agropecuaria/censoagro/2006/ defaulttab_censoagro.shtm>. Acesso em: 12 dez. 2016.

IPEA - Instituto de Pesquisa Econômica Aplicada. Como elaborar modelo lógico: roteiro para formular programas e organizar avaliação. Cassiolato M.; Gueresi, S. (Coord.). Brasília: IPEA, 2010. 
JANNUZZI, P. M. Avaliação de programas sociais no Brasil: repesando práticas e metodologias das pesquisas avaliativas. Planejamento e políticas públicas - PPP, n. 36, p. 251-275, 2011. KOTLER, P. Administração de marketing, 5. ed. São Paulo: Atlas, 1998.

MAIA, C. M. Percepções que permeiam o conceito de agricultura familiar e a cronologia da luta pela sustentabilidade: panorama nacional e internacional. In: SOGLIO, F. D.; KUBO, R. R. (Orgs.). Agricultura e Sustentabilidade (cap. 5, p. 75-96). Porto Alegre: Editora da UFRGS, 2009.

MALHOTRA, N. K. Pesquisa de Marketing: uma orientação aplicada, 3. ed. Porto Alegre: Bookman, 2001.

MALLMANN, L. Z. et al. Análise da sustentabilidade ambiental e econômica de pequena propriedade rural do RS. Estudo \& Debate, v. 20, n. 1, p. 7-20, 2013.

MDA - Ministério do Desenvolvimento Agrário. Conceito de agricultura familiar, 2016. Disponível em: <http://www.mds.gov.br/falemds/perguntas-frequentes/bolsa-familia/programas-complementares/beneficiario/agricultura-familiar>. Acesso em 12 jul. 2016.

MDS - Ministério do Desenvolvimento Social e Combate à Fome - MDS. Manual operativo: modalidade compra com doação simultânea operação por meio de termo de adesão, (versão 1.0, fevereiro de 2014), 2016a. Disponível em: <http://www.mds.gov.br/segurancaalimentar/ aquisicao-e-comercializacao-da-agricultura-familiar/entenda-o-paa/manualPAA_06.03.pdf $>$. Acesso em: 2 fev. 2016.

. Programa de aquisição de alimentos. 2016b. Disponível em: <http://www.mds.gov. br/segurancaalimentar/aquisicao-e-comercializacao-da-agricultura-familiar $>$. Acesso em: 12 fev. 2016.

Limite de compra de alimentos de agricultores familiares é ampliado, 2016c. Disponível em: <http://www.mds.gov.br/saladeimprensa/noticias/2014/agosto/paa-limite-de-compra-de-alimentos-de-agricultores-familiares-e-ampliado>. Acesso em 13 fev. 2016.

MPOG - Ministério do Planejamento, Orçamento e Gestão. Programa Gespública - Pesquisa de avaliação da Satisfação: Guia Metodológico (versão 1/2013). Brasília: MP, SEGEP, 2013.

NASCIMENTO, D. T. et al. Produção científica sobre políticas públicas para a agricultura familiar: o Programa de Aquisição de Alimentos (PAA). Encontro Nacional dos Cursos de Graduação em Administração, 26. Foz do Iguaçu, PR, 2015. Anais eletrônicos... Disponível em: <http://xxvi.enangrad.org.br/_assets/files/anais/2015/0307201516503869dc358f7171fbc469 36f974064cba09.pdf>. Acesso em 12 jul. 2016.

NAZZARI, R. K.; ZIMMERMANN, P. Agricultura familiar, capital social e cooperativismo. In: BRANDALISE, L. T.; BERTOLINI, G. R. F. (Orgs.). Gestão das Unidades Artesanais: uma tecnologia social para capacitação de empreendedores da agricultura familiar. Cascavel, PR: Edunioeste, 2015, 185p.

OCB - Organização das Cooperativas Brasileiras. Conceito de Cooperativismo, 2016. Disponível em: <http://www.ocb.org.br/site/cooperativismo/index.asp>. Acesso em 12 set. 2016.

PEREZ, F. I. C. Agricultura familiar superando desafios em contextos concorrenciais: estudo de caso realizado na região Noroeste e Missões do Estado do Rio Grande do Sul, 2011, 
148s. Dissertação (Mestrado em Extensão Rural) - Centro de Ciências Rurais, Universidade de Santa Maria, Santa Maria, RS, 2011. Disponível em: <http://cascavel.ufsm.br/tede/tde_busca/ arquivo.php?codArquivo=4439>. Acesso em: 15 de ago. 2016.

PGI - Plataforma de Gestão de Indicadores. Programa de Aquisição da Agricultura Familiar, 2015. Disponível em: <http://pgi.gov.br/pgi/indicador/pesquisar>. Acesso em: 2 fev. 2016.

ROSALEM, V. et al. Gestão de cooperativas: um estudo sob o olhar do cooperado. APGS, v. 1, n. 1, p. 46-66, 2009.

SCHMITZ, H.; MOTA, D. M. Agricultura familiar: categoria teórica e/ou de ação política? Fragmentos de Cultura. Goiânia, v. 18, n. 5/6, p. 435-446, mai./jun. 2008.

SCHNEIDER, S.; CAZELLA, A. A.; MATTEI, L. Histórico, caracterização e dinâmica do Pronaf - Programa Nacional de Fortalecimento da Agricultura Familiar (1995-2003). In: SCHNEIDER, S.; SILVA, M. K; MARQUES, P. E. M. (Orgs.). Políticas Públicas e Participação Social no Brasil, 2. ed. Porto Alegre: Editora da UFRGS, 2009, p. 21-49.

SCHULTZ, G. Relações com o mercado e [re] construção das identidades socioprofissionais na agricultura orgânica. In: SCHNEIDER, S.; GAZOLLA, M. (Orgs.). Os atores do desenvolvimento rural: perspectivas teóricas e práticas sociais. Porto Alegre: Editora da UFRGS, 2011.

SECCHI, L. Políticas Públicas: Conceitos, esquemas de análise, casos práticos, 2. ed. São Paulo: Cengage Learning, 2013.

SILVA, M. K.; MARQUES, P. E. M. Democratização e políticas públicas de desenvolvimento rural. In: SCHNEIDER, S.; SILVA, M. K.; MARQUES, P. E. M. (Orgs.). Políticas Públicas e Participação Social no Brasil (2. ed., p. 9-20). Porto Alegre: Editora da UFRGS, 2009.

TANACA, E. K. T.; SOUZA, H. M. FILHO; GANGA G. M. D. Proposta de um modelo de avaliação dos fornecedores do Programa de Aquisição de Alimentos (PAA): o caso do município de São Carlos - SP. Gest. Prod., v. 21, n. 4, 781-792, 2014.

WU, X. et al. Guia de políticas públicas: gerenciando processos (traduzido por Ricardo Avelar de Souza). Brasília: ENAP, 2014.

Recebido em: 10-01-2017

Aprovado em: 29-08-2017

Avaliado pelo sistema double blind review.

Editor: Coordenação do PPGA/UMESP

Disponível em http://mjs.metodista.br/index.php/roc 